\title{
Imbalanced post- and extrasynaptic SHANK2A functions during development affect social behavior in SHANK2-mediated neuropsychiatric disorders
}

\author{
Ahmed Eltokhi $\mathbb{1}^{1,2} \cdot$ Miguel A. Gonzalez-Lozano $\mathbb{1}^{3} \cdot$ Lars-Lennart Oettl $\mathbb{C}^{4} \cdot$ Andrey Rozov $\mathbb{1}^{5,6,7} \cdot$ Claudia Pitzer $^{8}$. \\ Ralph Röth ${ }^{2}$ - Simone Berkel $\mathbb{1}^{2} \cdot$ Markus Hüser ${ }^{1} \cdot$ Aliona Harten ${ }^{1} \cdot$ Wolfgang Kelsch $\mathbb{D}^{4,9} \cdot$ August B. Smit $\mathbb{C}^{3}$. \\ Gudrun A. Rappold $\mathbb{D}^{2,10} \cdot$ Rolf Sprengel $\mathbb{D}^{1,10}$
}

Received: 12 October 2020 / Revised: 11 April 2021 / Accepted: 20 April 2021 / Published online: 21 May 2021

(c) The Author(s) 2021. This article is published with open access, corrected publication 2021

\begin{abstract}
Mutations in SHANK genes play an undisputed role in neuropsychiatric disorders. Until now, research has focused on the postsynaptic function of SHANKs, and prominent postsynaptic alterations in glutamatergic signal transmission have been reported in Shank KO mouse models. Recent studies have also suggested a possible presynaptic function of SHANK proteins, but these remain poorly defined. In this study, we examined how SHANK2 can mediate electrophysiological, molecular, and behavioral effects by conditionally overexpressing either wild-type SHANK2A or the extrasynaptic SHANK2A(R462X) variant. SHANK2A overexpression affected pre- and postsynaptic targets and revealed a reversible, development-dependent autism spectrum disorder-like behavior. SHANK2A also mediated redistribution of $\mathrm{Ca}^{2+}$-permeable AMPA receptors between apical and basal hippocampal CA1 dendrites, leading to impaired synaptic plasticity in the basal dendrites. Moreover, SHANK2A overexpression reduced social interaction and increased the excitatory noise in the olfactory cortex during odor processing. In contrast, overexpression of the extrasynaptic SHANK2A(R462X) variant did not impair hippocampal synaptic plasticity, but still altered the expression of presynaptic/axonal signaling proteins. We also observed an attention-deficit/ hyperactivity-like behavior and improved social interaction along with enhanced signal-to-noise ratio in cortical odor processing. Our results suggest that the disruption of pre- and postsynaptic SHANK2 functions caused by SHANK2 mutations has a strong impact on social behavior. These findings indicate that pre- and postsynaptic SHANK2 actions cooperate for normal neuronal function, and that an imbalance between these functions may lead to different neuropsychiatric disorders.
\end{abstract}

These authors contributed equally: Miguel A. Gonzalez-Lozano, LarsLennart Oettl, Andrey Rozov.

These authors share senior authorship: Gudrun A. Rappold, Rolf Sprengel.

Supplementary information The online version contains supplementary material available at https://doi.org/10.1038/s41380021-01140-y.

Gudrun A. Rappold

Gudrun.Rappold@med.uni-heidelberg.de

$\triangle$ Rolf Sprengel

Rolf.Sprengel@mpimf-heidelberg.mpg.de

Extended author information available on the last page of the article

\section{Introduction}

Coding mutations in SHANK1-3 genes have been associated with autism spectrum disorder (ASD), and SHANK2 and SHANK3 mutations were also identified in other neuropsychiatric disorders, including schizophrenia [1]. In addition, SHANK2 and SHANK3 mutations are tightly linked with intellectual disability, while SHANK1 mutations have been identified in ASD patients with normal intelligence [2]. All three SHANK genes encode an evolutionarily preserved protein domain structure, which suggests that SHANK proteins have different but related functions at the excitatory synapses, especially in glutamate receptor function and assembly during development [3].

SHANK genes generate multiple isoforms, some of which lack several protein-protein interaction domains. The different isoforms of the SHANK proteins have been suggested to determine the different organization of the 
postsynaptic proteins at different developmental stages and/ or different brain regions [4]. Several Shank3 knockout (KO) mouse models targeting different isoforms have been generated, which showed diverse phenotypes on behavioral, molecular, and electrophysiological levels [4, 5]. This revealed the specific functions of different SHANK isoforms in determining how proteins are structured within the postsynaptic density (PSD) (for a review, see [6]). However, the existing gene-targeted conventional and conditional Shank2 KO mouse models could not fully dissect the complex function of SHANK2 and its isoforms [5]. Thus, both Shank2 $2^{\Delta e x 15-16}$ and Shank2 $2^{\Delta e x 16}$ KO mouse models displayed comparable ASD-like phenotypes but with different endophenotypes, and Shank $2^{\operatorname{Lex} 24}$ mice exhibited bipolar-associated mania-like behaviors including hyperactivity and decreased repetitive behaviors (for a review, see [5]). The behavioral differences between the three mouse models were extended to the molecular, electrophysiological, and synaptic composition, as well as to the anatomical levels. Therefore, the simple suggestion of a hypomorphic SHANK does not explain the highly variable phenotypes in Shank KO mice and patients with SHANK mutations. Other putative SHANK isoforms may still be present and could play additional roles, which may have obscured the detailed functional analysis of SHANK and masked specific phenotypes in Shank KO mouse models [7].

Recently, several studies have suggested presynaptic functions of the SHANK protein family $[8,9]$, which could be overshadowed by the prominent postsynaptic changes in Shank KO mouse models [10]. These possible functions on the composition and operation of the axon terminals add another layer of complexity to SHANK functions and may be a component of the diverse phenotypes in patients and Shank KO mice. To investigate this hypothesis and dissect the pre- and postsynaptic functions, we dominated the structure and organization of the SHANK scaffold in well-defined neuronal subtypes by using the classical gainof-function approach and overexpressed SHANK2A, a brain-specific SHANK2 isoform, or the extrasynaptic SHANK2A(R462X) variant. We generated a doxycycline (Dox)-controlled transgenic mouse line, in which the transgenic SHANK2A isoform is expressed in those brain regions that are implicated in neuropsychiatric disorders (cortex, hippocampus, and striatum) [11]. Analogously, we generated a second transgenic mouse line expressing the SHANK2A(R462X) variant found in one ASD patient [12]. In a previous in vitro study, we provided direct evidence that the C-terminal SHANK2A SAM domain is essential for the postsynaptic localization of SHANK2A: The Venustagged SHANK2A(R462X) that is lacking the SAM domain could only be detected in the somata, but not in the dendritic spines [13]. Since SHANK2A(R462X) expression is associated with ASD, this suggests other extrasynaptic functions of SHANK2. Already in 1998, Du et al. suggested a role of CortBP1 (now renamed SHANK2 [14]) in axonal outgrowth, growth cone mobility, and presynaptic specializations in cultured neurons [15]. Our comparative analysis of both mouse lines revealed for the first time the necessity of its protein domains to perform its effects on axonal/preand postsynaptic functions and on both postsynaptic and extrasynaptic dysfunction in the progression of different neuropsychiatric disorders.

\section{Results}

\section{Generation of $T g^{\text {SHANK2A/tTA }}$ (SH-WT) and $T g^{\text {SHANK2A }}$ (R462X)/tTA (SH-RX) mice}

For a conditional overexpression of the SHANK2A isoform in the forebrain of mice, we employed the well-established Dox-controlled Tet-Off system (Fig. 1A). Using this system, we obtained SHANK2A and SHANK2A(R462X) overexpressing mouse lines, named SH-WT and SH-RX, respectively, with comparable Dox-controlled transgene expression levels and expression patterns in excitatory neurons in the hippocampus, cortex, inhibitory medium spiny neurons (MSN) in the striatum and granule cells in the olfactory bulb (Fig. 1B, C; Fig. S1-S3). In the hippocampus, quantitative n-Counter mRNA analysis revealed a 12-fold overexpression for both bicistronic Venus2ASHANK2A and Venus2A-SHANK2A(R462X) transcripts when compared to the endogenous Shank2 gene-derived mRNA, and a 1.6-fold increased expression relative to the sum of all endogenous Shanks (Shank1-3) (Fig. 1D). Endogenous Shankl and Shank3 mRNA and protein levels were neither affected by SHANK2A nor by SHANK2A (R462X) transgene overexpression (Fig. 1E, F), excluding a feedback regulation of Shank gene expression. To eliminate the developmental expression of the functional Camk2atTA (Fig. S3) and thus the developmental expression of the transgenic SHANK2As, pregnant mice received a Dox diet until labor, causing a complete switch-off of the tTAcontrolled transgene expression till P10 (Fig. 1G). Doxtreatment of adult transgenic mice for at least one month triggered an efficient shut-down of the transgene expression in adult SH-WT ${ }^{\text {Ad-off }}$ and SH-RX ${ }^{\text {Ad-off }}$ mice (Fig. 1H).

\section{Transgenic SHANK2A expression induced a shift of $\mathrm{Ca}^{2+}$-permeable AMPARs in CA1 cells, and SHANK2A (R462X) increased the branching of CA1 basal dendrites}

Since the postsynaptic glutamatergic system is the main focus in research on shankopathies [16] and since our study 
A Transgenic constructs

SH-WT (Tg SHANK2AITA $)$
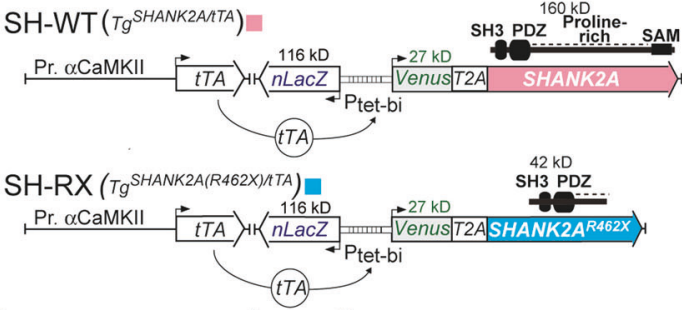

C Transgene expression pattern
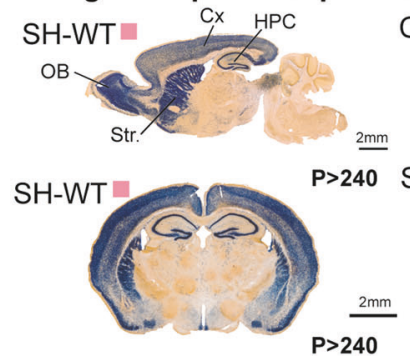

Ctrl. $\square$
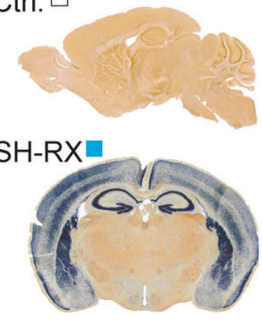

E

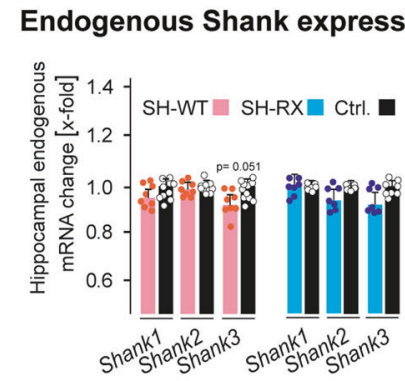

B Transgene expression

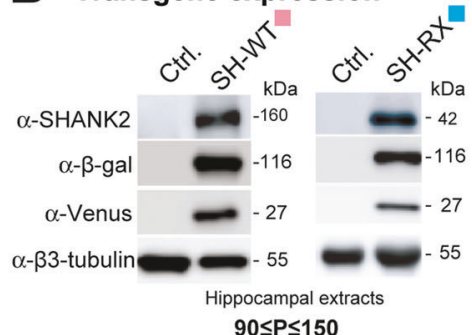

D Shank and SHANK2 expression

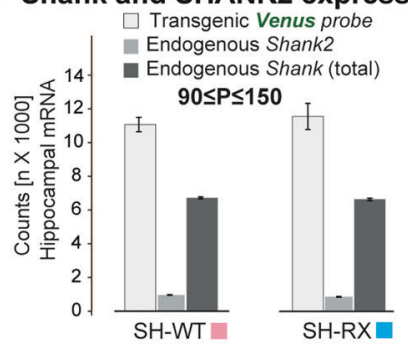

G Transgenic SHANK2 expression 'off' during development (P10-on)
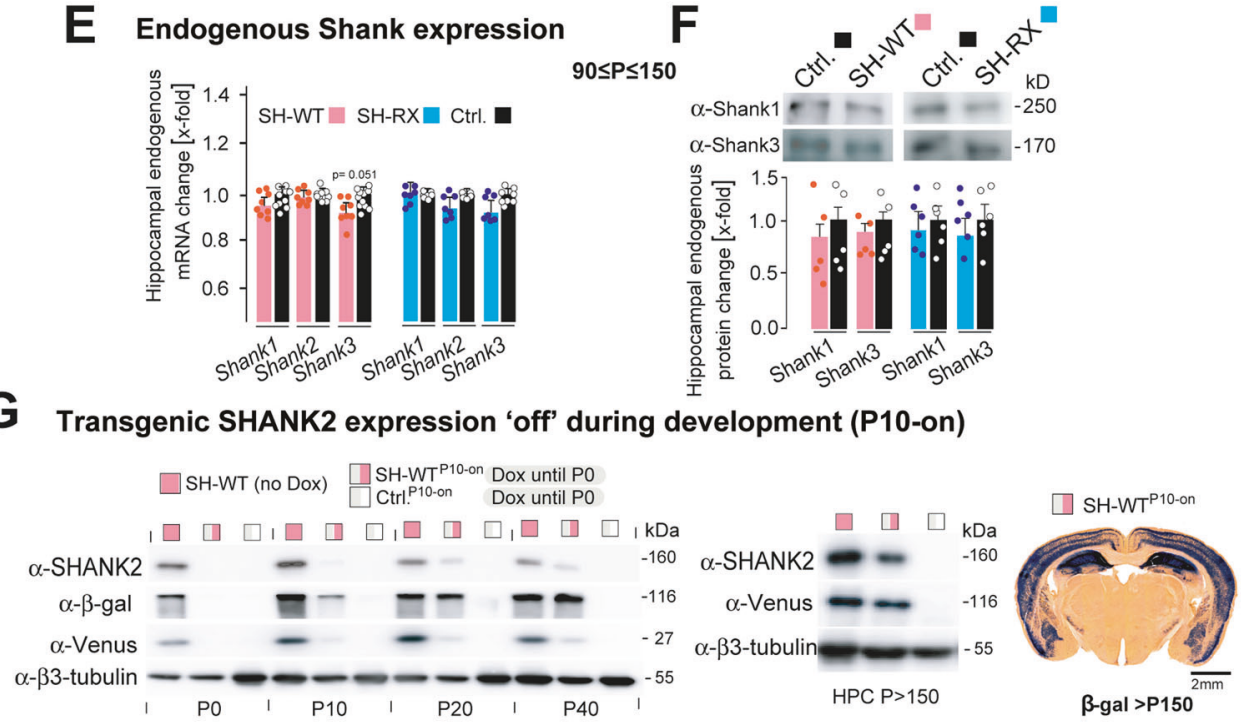

H Transgenic SHANK2 expression 'off' after development after (Ad-off)
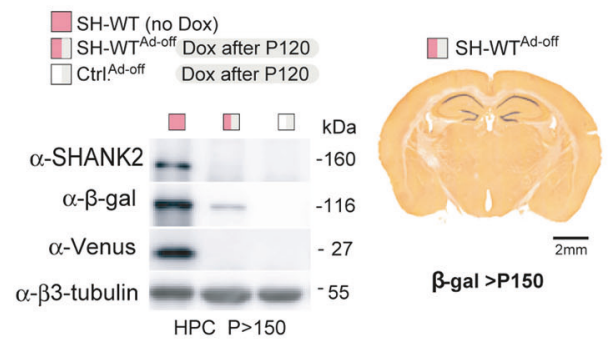

ß-gal >P150

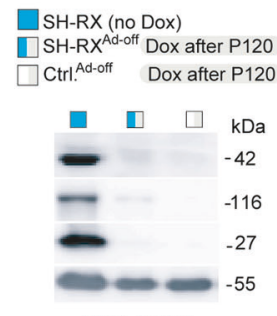

HPC $P>150$

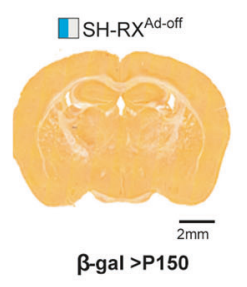

$\beta$-gal > P150 focused mainly on the well-studied synaptic transmission and plasticity of hippocampal synapses, we measured mRNA and protein expression of NMDA, AMPA, and metabotropic glutamatergic receptors in the hippocampi of SHANK2A and SHANK2A(R462X) overexpressing mice. On the mRNA level, SH-WT showed a downregulation of the NMDAR genes Grin2a and 2b, AMPAR genes Grial and 2, and metabotropic glutamatergic receptor Grml and 5 (Fig. 2A). Only the downregulation of Grial and 2 was confirmed on the protein level (Fig. 2B and Fig. S4A). For SH-RX, the expression of Grial and 2 was downregulated, which was confirmed by immunoblots (Fig. 2A, B and 
Fig. 1 Generation and characterization of SH-WT and SH-RX mice. A Scheme of the two transgenes used for the overexpression of SHANK2A and SHANK2A(R462X) in glutamatergic neurons of the forebrain. The transcription activator (tTA) for the bidirectional Ptet-bi promoter of the SHANK2A and SHANK2A(R462X) transgenes can be inactivated by the presence of doxycycline (Dox). Black arrows indicate transcriptional start sites. SHANK2A isoform constitutes of 4 protein domains, whereas SHANK2A(R462X) lacks part of prolinerich and the SAM domains. B Hippocampal protein lysates of SH-WT and SH-RX animals showed comparable immunosignals of the transgene expressing SHANK2A and SHANK2A(R462X). The BetaGalactosidase ( $\beta-\mathrm{Gal}$ ) and Venus were used as additional markers. The proteins were visualized by immunoblotting using antibodies specific to the human SHANK2, $\beta$-galactosidase, and Venus. $\beta 3$-tubulin was used as a loading control. $\mathbf{C}$ top row: $\beta-G a l$ activity was restricted to forebrain areas, as shown in sagittal brain sections of SH-WT mice. XGal on control mice showed no staining. $\mathbf{C}$ bottom row: $\mathrm{X}$-Gal stained coronal brain sections from SH-WT and SH-RX mice (scale bars: 2 $\mathrm{mm})$. D nCounter analysis revealed 12-fold mRNA expression of Venus (11,064 and 11,550 counts) compared to the endogenous Shank2 level in the hippocampi of SH-WT (962 counts) and SH-RX (859 counts) mice, respectively. 1.6-fold higher mRNA expression of Venus compared to endogenous Shanks (Shank1 + Shank2 + Shank3) (6717 and 6630 counts) was measured in eight SH-WT and 7 SH-RX mice. $\mathbf{E}$ nCounter analysis revealed no change in the mRNA expression of Shank1-3 in the hippocampi from SH-WT or SH-RX animals ( $n=8$ SH-WT and 11 control mice; $n=7$ SH-RX and seven control mice; 3-5 months in age). F No change on SHANK1 and SHANK3 expression in the total protein lysates from SH-WT or SH-RX hippocampi $(n=5 \mathrm{SH}-\mathrm{WT}$ mice and 5 control mice; $\mathrm{n}=6 \mathrm{SH}-\mathrm{RX}$ mice and 6 control mice; 3-5 months old). G (left) Dams were treated with Dox until labor (which precludes SHANK2A expression) and the brains of offspring (SH-WT $\left.{ }^{\mathrm{P} 10 \text {-on }}\right)$ and littermate controls $\left(\mathrm{Ctrl}^{\mathrm{P} 10-\mathrm{on}}\right)$ analyzed for residual human SHANK2A, $\beta$-gal, and Venus expression. Protein lysates of the forebrain were used at different postnatal stages (P0-P40) from SH-WT ${ }^{\mathrm{P} 10-\mathrm{on}}$ and $\mathrm{Ctrl}^{\mathrm{P} 10-\mathrm{on}}$ mice. The expression of the $\beta$-gal and Venus transgenes started at around P10. G (middle) Total protein lysates of the hippocampus from adult $\mathrm{SH}-\mathrm{WT}^{\mathrm{P} 10-\mathrm{on}}$ and Ctrl. ${ }^{\text {P10-on }}$ mice were analyzed by immunoblotting with the humanspecific SHANK2 and Venus antibodies and revealed high expression levels of SHANK2A and Venus, but lower levels compared to the positive control mice. G (right) $\beta$-gal expression of the nlacZ gene can be detected at the cellular level of adult SH-WT ${ }^{\mathrm{P} 10 \text {-on }}$ mice by X-gal staining (scale bar: $2 \mathrm{~mm}$ ). H Protein lysates of the hippocampi from adult SH-WT, SH-RX, and respective littermate control mice treated for 1 month with Dox (SH-WT ${ }^{\text {Ad-off }}$, SH-RX ${ }^{\text {Ad-off }}$, and Ctrl. ${ }^{\text {Ad-off }}$ ) were analyzed by immunoblotting using the human-specific SHANK2, $\beta$ gal, and Venus antibodies. Immunoblots revealed an almost complete absence of $\beta$-gal and complete absence of Venus and polycistronic SHANK2 expression in Dox-treated mice ( 7 months). Some $\beta$-gal expression of the nlacZ gene can still be detected by X-Gal staining at the cellular level in SH-WT ${ }^{\text {Ad-off }}$, but not SH-RX ${ }^{\text {Ad-off }}$ mice (scale bars: $2 \mathrm{~mm}$ )

Fig. S4A). Whereas Grin2a, Grin2b, and Grial expressions were normal when SHANK2A was suppressed during development or when the transgenic SHANK2A and SHANK2A(R462X) expression was suppressed in adulthood. The mRNAs for the AMPAR subunits 2,3 and mGluRs were reduced when the SHANK2A transgene was transiently expressed (Fig. S4B, C). On the other hand, suppression of SHANK2A(R462X) transgene expression in adult mice rescued the reduction of Grial but not Gria2 expression.
Despite the reduced global hippocampal Grial/2 mRNA and GluA1/2 protein levels in both SH-WT and SH-RX mice, electrophysiological recordings from the CA1 pyramidal cells in the hippocampus revealed regular synaptic NMDAR and AMPAR currents in basal and apical dendrites in SH-RX mice compared to controls. In the apical dendrites of SH-WT mice, a specific increase of the AMPAR response could be recorded (Fig. 2C). This selective enhancement of AMPAR-mediated EPSC was mediated by an AMPAR subtype switch from a low conductance GluA2-containing to a high conductance AMPAR subtype lacking GluA2. This was evidenced by a robust reduction of the AMPAR currents in the apical dendrites by the selective GluA2-lacking AMPAR channel blocker, 1-naphthyl acetyl spermine (Naspm) in SH-WT mice (Fig. 2D). Simultaneously, with the increased sensitivity of apical dendrites to Naspm the basal dendrites became Naspm resistant (Fig. 2D), indicating a specific subcellular reduction of $\mathrm{Ca}^{2+}$-permeable AMPARs in basal dendrites in SH-WT mice. The decrease of $\mathrm{Ca}^{2+}$-permeable AMPARs in basal dendrites could be monitored also by the lack of pairinginduced long-term potentiation (LTP), where $\mathrm{Ca}^{2+}$-permeable AMPARs contribute to LTP induction [17, 18]. The increased level of high conductance AMPARs in apical dendrites did not change or facilitate LTP levels (Fig. 2E, F). In SH-RX mice, as expected from the somatic expression of SHANK2A(R462X) [13], the transgenic SHANK2A(R462X) neither affected the AMPAR currents nor the AMPAR subtype in CA1 pyramidal cells (Fig. 2C, D). A trend towards a subcellular-specific increase of LTP together with an increased branching of CA1 basal dendrites in the stratum oriens in SH-RX mice could be monitored (Fig. 2F-H). The slightly increased CA3-to-CA1 LTP in SH-RX mice and the AMPAR subtype switch towards $\mathrm{Ca}^{2+}$-permeable AMPAR in apical and towards $\mathrm{Ca}^{2+}$ impermeable AMPAR in basal dendrites of SH-WT mice, cannot be explained by reduced GluA1 levels, indicating that the reduced glutamate receptor levels in hippocampal extract reflect the pool of extrasynaptic receptors. Thus, our electrophysiological experiments show that SHANK2A modulates the AMPAR levels on a subcellular level in synapses to modulate the synaptic plasticity, and that for this modulation the SAM domain is essential. When SHANK2 is expressed without the SAM domain, this SHANK2A loses its ability as a postsynaptic organizer scaffold protein. This provides direct functional evidence that SHANK2A(R462X) does not act as an AMPAR organizer in the postsynapse.

\section{Comparative proteomic and pathway analysis of the hippocampus highlights targets for axonal/ presynaptic function in SH-WT and SH-RX and additional postsynaptic targets in SH-WT only}

To extend the quantification of our preselected mRNA expression and immunosignal analysis (Fig. 1E, F and 

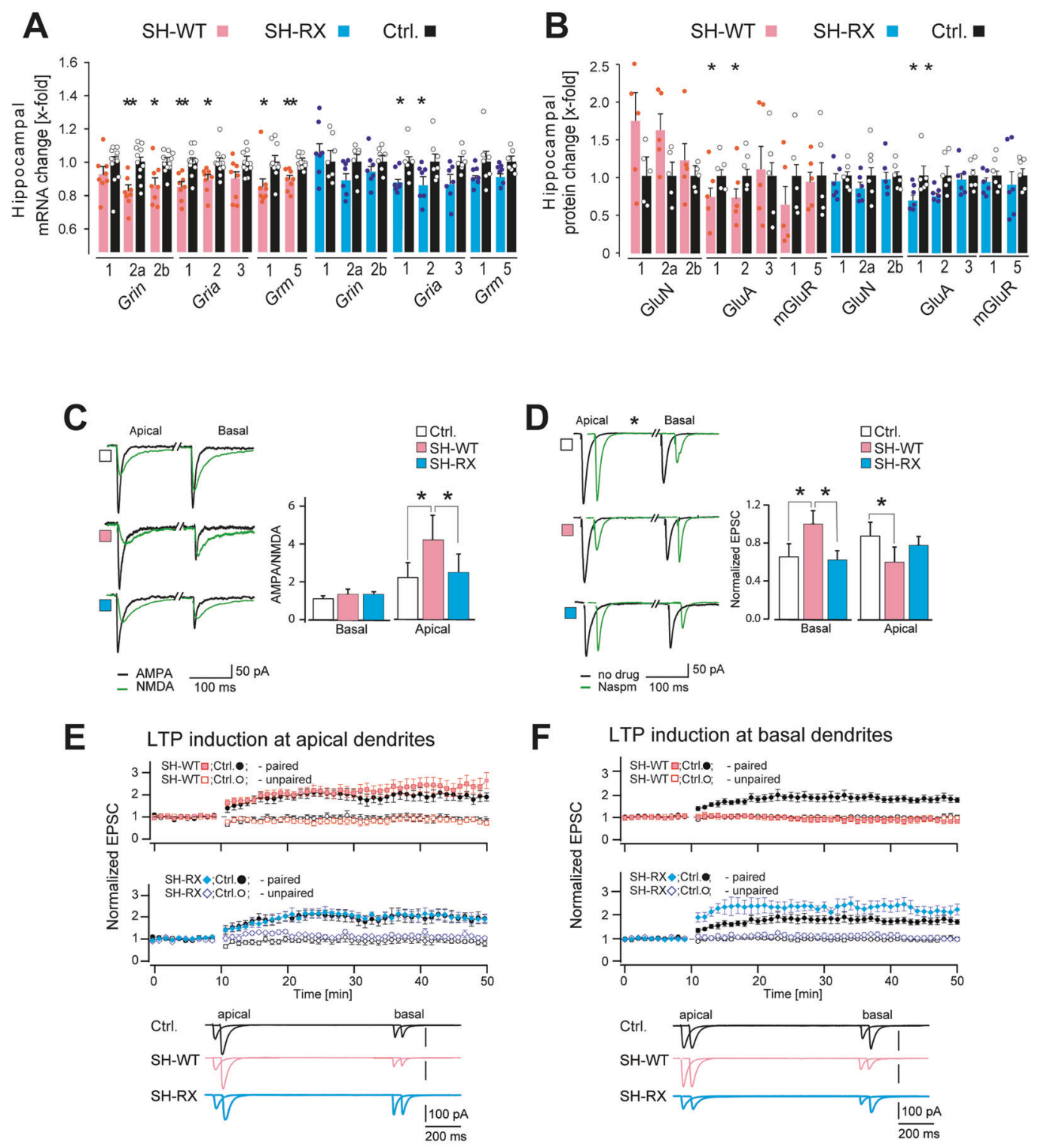

F

= LTP induction at basal dendrites
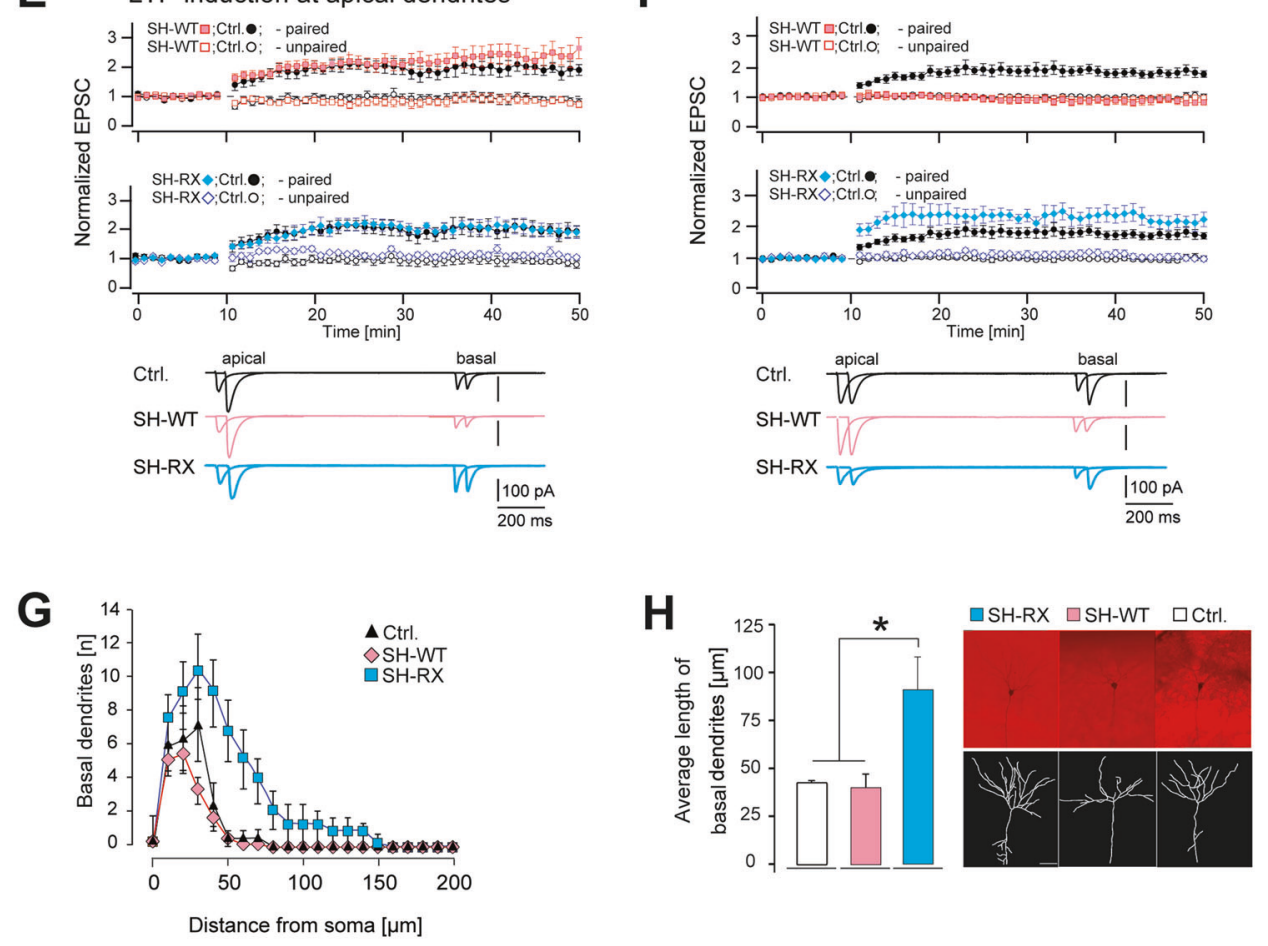

Fig. 2A, B), we screened more than 2000 proteins in the synaptic-enriched P2 fractions and employed a quantification by mass spectrometry (MS) combined with and ConsensusPathDB/KEGG pathway [19] and SYNGO [20] analyses to identify alterations in proteins that are involved in synaptic function. As input data, the protein-rich fraction (P2 fraction) - representing a crude purification of proteins

outside of the cell soma-was used. To avoid a preselection of our protein pool to only proteins of the synaptic scone, we did not use the PSD-enriched fraction, which is strongly enriched by exclusively postsynaptic proteins.

By using the SWATH-MS acquisition approach [21, 22], a total of 2466 proteins were identified and quantified based on 9206 peptides present in all samples (Supplementary 
Fig. 2 Structural alterations and AMPAR conductance imbalance in apical and basal dendrites in the CA1 hippocampal region of SH-WT and SH-RX mice. A Hippocampal mRNA expression of SHWT mice showed on average a down-regulation of NMDA (Grin2a and Grin2b), AMPA (Grial and Gria2), and metabotropic glutamate (Grm1 and Grm5) receptor genes using nCounter analysis $(n=8 \mathrm{SH}-$ WT and 11 control mice, 3-5 months). Expression analysis of SH-RX hippocampi revealed a significant down-regulation of AMPAR genes (Grial and Gria2) ( $n=7$ SH-RX and 7 control mice, 3-5 months). B Total protein lysate analysis of SH-WT hippocampi confirmed the downregulation of AMPAR subunits GluA1 and $2(n=5$ mice for each genotype, 3-5 months). For SH-RX, the down-regulation of the AMPAR subunits GluA1 \& 2 was also confirmed $(n=6$ mice for each genotype, 3-5 months). Unpaired two-tailed Student's $t$ test followed by the Benjamini-Hochberg test, $* p \leq 0.05, * * p \leq 0.01$. C. AMPA/ NMDA ratio measurements revealed an increase of the ratio in SH-WT but not in SH-RX mice in the apical dendrites in the CA1 hippocampal region compared with control mice. No difference in the AMPA/ NMDA ratio was found between SH-WT, SH-RX, and control mice in the basal dendrites in the CA1 hippocampal region. D Naspm treatment, a blocker of AMPARs lacking the GluA2 subunit, decreased the current in the apical dendrites of SH-WT mice compared to SH-RX and control mice, which showed a reduced current in the basal dendrites. E SH-WT and SH-RX mice revealed no difference in the pairinginduced LTP in the apical dendrites compared to control mice. F Synapses at basal dendrites of SH-WT mice showed no LTP and those of SH-RX mice showed a nonsignificant trend towards increased LTP compared to control mice ( $n=6$; unpaired two-tailed Student's $t$ test, $* p \leq 0.05$, 4-6 weeks). G Sholl analysis showed an increased number of basal dendrites and $\mathbf{H}$ longer basal dendrites in CA1 pyramidal cells of SH-RX animals compared to SH-WT and control mice $(n=3$ mice for each genotype; One-way ANOVA followed by the turkey multiple comparison test, ${ }^{*} p \leq 0.05$ ). Representative pictures of biocytin-filled neurons in CA1 hippocampal regions from SH-RX, SH-WT and control mice along with the respective reconstruction of their basal and apical dendrites. Scale bar: $50 \mu \mathrm{m}$. Standard errors are given as SEM for $\mathbf{A}, \mathbf{B}, \mathbf{G}, \mathbf{H}$ and as SD for $\mathbf{C}-\mathbf{F}$.

Data 1). The median coefficient of variation (Fig. S5A) of the protein quantification was $11 \%, 13 \%$, and $10 \%$ in control, SH-WT, and SH-RX groups, respectively (Fig. S5B). Only minor differences in variation were observed between a protein identified with only one peptide and with two or more peptides (Fig. S5C). The statistical analysis revealed 104 and 55 proteins in adult SH-WT and SH-RX mice, respectively, with significantly different protein levels compared to controls (FDR corrected $p<0.05$; Table S1, S2). The proteomic analysis was performed using statistics corrected for multiple testing. In SH-WT mice, the total SHANK2 level (mouse and human SHANK2A protein) was 2.4-fold increased, while Shank1 and Shank3 reached a 0.66 and 0.74 -fold score of the levels compared to the synaptic-enriched Shank1 and Shank3 from control littermates (Table S1), indicating that (i) on the postsynaptic level, SHANK2A overexpression displaced Shank1 and Shank3 and that (ii) the effect of transgenic overexpression in the synaptic-enriched P2 fraction is not as strong as suggested by the total mRNA and protein levels (Fig. 1D). In SH-RX mice, the transgenic SHANK2A(R462X) expression neither changed the ratio of the endogenous, synapse-enriched Shank1, 2, or 3 nor did it affect the synaptic enrichment of other major postsynaptic proteins (Table S2), in line with the somatic and extrasynaptic localization of the SHANK2A(R462X) variant previously seen in rat primary neurons [13].

The cellular component and biological process analysis by "ConsensusPathDB" identified potential changes in the postsynaptic density and synaptic membrane in SH-WT and changes in axonal components in SH-RX mice. These affected pathways suggested alterations in the dendritic organization, behavior, and vocalization in SH-WT, but not in SH-RX mice (Fig. 3A, B). Similarly, the molecular function analysis, as well as the KEGG pathway analysis, predicted alterations in glutamatergic synapses in SH-WT mice. In sharp contrast, in SH-RX mice the ConsensusPathDB analysis pointed to significant alterations in axon guidance due to semaphorin receptor-controlled pathways (Fig. 3C, D).

Similarly, the enrichment analysis in SynGO [20] of protein levels identified pre- and postsynaptic changes in SH-WT and underlined the alterations in presynaptic/axonal functions and vesicular release in SH-RX mice (Fig. S6). This result was also obtained when we removed the one-hit peptides, or the SHANK proteins from the SYNGO input list of altered proteins (data not shown). Those data provide strong indications for additional SHANK2A-induced modulation of presynaptic/axonal functions most likely by promoting neuronal outgrowth and/or synapse formation. For the presynaptic action, the SHANK2A C-terminus is dispensable, whereas, for the well-described postsynaptic action, the SHANK2A full-length protein is necessary.

Concerning the presynaptic alterations, the SH-WT and SH-RX mice share 23 differentially-expressed synapseenriched proteins in the hippocampal P2 fraction (Table S1, S2). Three of these 23 proteins, Amisyn (Stxbp6), R-PTPN2 (Ptprn2), and Copine V (Cpne5), are already differentially expressed in the $T g^{\text {Camk2a-tTA }}$ mice compared with wild-type controls (Table S3). This can be explained by the transgenic insertion of the Camk2a-tTA transgene in Chr. 12, which triggered a $508 \mathrm{~kb}$ chromosomal deletion in Chr. 12, removing six genes including Ptprn2 [23]. In total, the hippocampal P2 fraction of SH-WT and SH-RX mice revealed 12 and 9 altered gene products, respectively, that were already altered in the hippocampal fraction of $T^{\text {Camk2a-tTA }}$ mice (Tables S1-S3). From the remaining 20 SH-WT and SH-RX gene products with different P2 levels in hippocampi, 6 proteins were detected by using only a single peptide in the MS and might need further validation [24]. Notably, from those 20 proteins, 13 proteins are involved in axonal or neurodevelopmental functions and only 7 also in postsynaptic function, whereas the contribution of differentially changed postsynaptic proteins in the $\mathrm{P} 2$ fraction was much more pronounced in SH-WT 

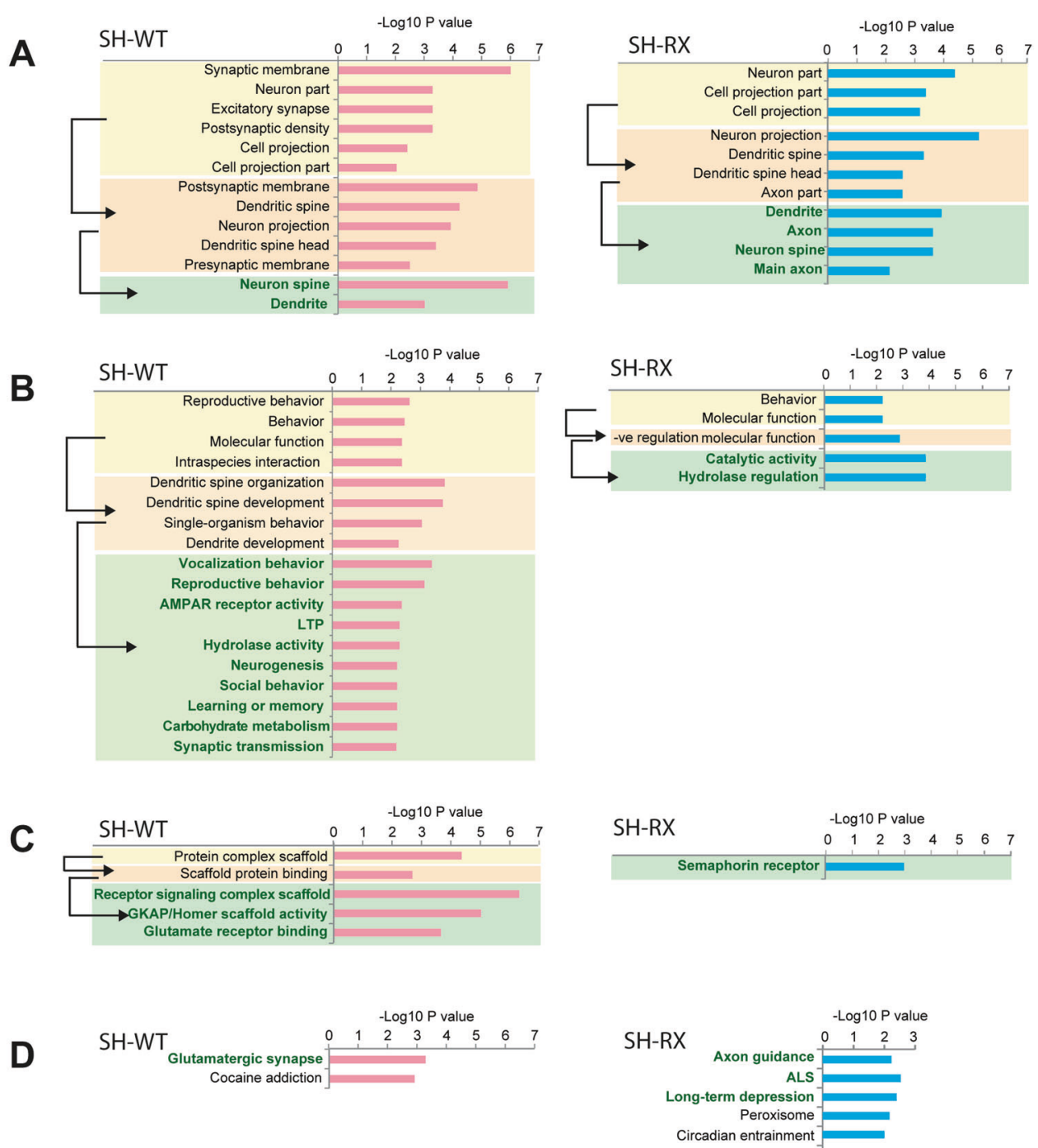

Fig. 3 Analysis of hippocampal synapse-enriched protein fractions of SH-WT and SH-RX mice revealed line-specific alterations in pre- and postsynaptic pathways. A Based on the abundant proteins of hippocampal synapses, the cellular component analysis of ConsensusPathDB database proposed that the synaptic membrane, neuron part, postsynaptic density, cell projections, and neuronal spines might be affected in SH-WT and SH-RX mice. B The biological process analysis proposed significant alterations in the behavior, dendritic organization, and altered vocalization for SH-WT mice but not for SHRX mice. C The molecular function analysis predicted alterations in

mice. Unexpectedly, from the major players of the glutamatergic systems, only GluA1 (grial) levels were altered the synaptic-enriched fractions of SH-WT and SH-RX mice, and Homer2 (homer2) and mGluR3 (Grm3) levels were altered in the SH-WT mice. Other major players of the glutamatergic system were detected in the pool of analyzed proteins but their protein levels were comparable to control mice.

Strikingly, in both SH-WT and SH-RX P2 protein fractions, proteins with the most significant changes compared the scaffold organization of glutamatergic synapses for SH-WT mice and alteration in the semaphorin receptor function for axon guidance in SH-RX mice. D The KEGG pathway analysis suggested that the glutamatergic synapses are affected in SH-WT, whereas the axon guidance pathway is most likely impaired in SH-RX mice. A-C ConsensusPathDB identified on level 2, are given in the yellow field and were eventually more specified in the third (pink) and fourth level (green). $\mathrm{LTP}=$ Long-term potentiation; $\mathrm{ALS}=$ Amyotrophic lateral sclerosis.

with control fractions (Kif1a, Mycbp2, Rae1, Map7d2, and Apba2) promote axonal and neuronal outgrowth as suggested by their enhanced levels in the P2 fraction. Some of these proteins have been described as risk genes for neuropsychiatric disorders. Kifla, for example, is a key motor protein for the efficient axonal retrograde transport of presynaptic protein components [25]. Kif1a is associated with non-syndromic intellectual disability and spastic paraplegia [26-28]. Mycbp2 belongs to the family of PHR proteins, which function in all key steps of axonal development. But 
dendritic arborization was also found to be affected by Mycbp 2 mutations. Thus, PHR proteins can have opposing effects on axon termination and dendrite extension in a single neuron (for a review, see [29]). A causal link between Mycbp2 variants and ASD has not been shown so far [30]. PHR proteins interact with Rae1 [31], which, like Mycbp2, is also significantly enriched in the P2 fraction of our SH-WT and SH-RX mice. Map7d2 promotes cargo transport in the axon [32]. The Apba2 gene encodes amyloid-beta precursor protein-binding 2 (Apba2/Mint2). Apba2/Mint2 is a presynaptic adaptor protein involved in neurexin trafficking and neuronal function, and several nonsynonymous MINT2 variants have been identified in ASD patients [33]. We did not include NDRG3 in this list, since NDRG3 is expressed mainly in the nucleus. It is known to be involved in aggressive behavior, but additional research is required to identify a potential role for NDRG3 within the nervous system [34].

Together, these data provide strong evidence for an additional, unexpected presynaptic/axonal role of SHANK2A that can promote either directly or indirectly axonal outgrowth and presynaptic function.

\section{SH-WT mice exhibited ASD-like and SH-RX mice ADHD-like phenotypes}

To determine the effect of presynaptic dysfunction in SH-RX mice and the combined pre- and postsynaptic dysfunction in SH-WT mice on the pathophysiology of neuropsychiatric disorders, we analyzed the behavior of the different mouse cohorts. We found that SH-WT mice showed a reduced body weight and ASD-typical intensive rearing, hyperactivity, anxiety, impairment in nest building and burrowing, novel object recognition, direct social interaction, and deficits in the social preference tests (Fig. 4A and Fig. S7A, 8A). A direct causal link between transgenic SHANK2A expression and alterations in the behavioral phenotype could be demonstrated by inhibiting the transgenic SHANK2A transcription during prenatal and early postnatal development in $\mathrm{SH}_{-} \mathrm{WT}^{\mathrm{P} 10-\mathrm{on}}$ mice by Dox-treatment (Fig. 1G). In adult SH-WT ${ }^{\mathrm{P} 10-\text { on }}$ mice, the increased rearing, hyperactivity, anxiety, burrowing impairment, and reduced body weight were strongly attenuated compared to Dox-naive SH-WT mice (Fig. 4B and Fig. S7B, 8B). Importantly, $\mathrm{SH}_{-} \mathrm{WT}^{\mathrm{P} 10-\mathrm{on}}$ mice displayed regular nest building and novel object recognition, normalized direct social interaction, vocalization, and social preference in the threechamber social test (Fig. 4B). Thus, the transgenic SHANK2A overexpression during development is causally linked to the social impairments in ASD.

By turning off transgenic SHANK2A expression in adult animals (SH-WT ${ }^{\text {Ad-off }} ;$ Fig. $1 \mathrm{H}$ ), we found that $\mathrm{SH}-\mathrm{WT}^{\text {Ad-off }}$ mice still displayed hyperactivity, increased anxiety, and alterations in rearing, burrowing, and nest building (Fig. 4C and Fig. S7C, 8C). However, the social impairment and novelty interaction of $\mathrm{SH}-\mathrm{WT}^{\text {Ad-off }}$ were comparable to controls (Fig. 4C), which illustrates that regarding social behavior, the neurodevelopmental SHANK2A dysfunction in the neuronal network can be reversed, as shown for both SHANK2 [35] and SHANK3 [36].

In SH-RX mice, the hyperactivity, anxiety, and burrowing impairment were less pronounced compared to $\mathrm{SH}-$ WT mice (Fig. S7D, 8D). But in sharp contrast to SH-WT mice, the repetitive self-grooming was reduced in the night and the light phases and novel object recognition, vocalization, and direct social interaction were significantly enhanced compared to littermate controls (Fig. 4D). Again -analogous to SH-WT mice-the switch-off of the SHANK2A(R462X) overexpression in adult mice (SH$\mathrm{RX}^{\text {Ad-off }}$ ) triggered a rescue of the enhanced social activities (in this case attenuation of hypersociablity) but failed to normalize the hyperactivity, burrowing impairment or reduced self-grooming (Fig. 4E and Fig. S7E, 8E).

The cognitive function of the mice was tested in the hippocampus-dependent Puzzle box task [37] and in the classical fear conditioning task. The SH-WT mice showed mild impairment in the memory-dependent executive function and no impairment in fear memory, whereas the SH-RX mice showed poor memory in both tasks (Fig. S9).

To assess if the hyperactivity in SH-RX mice resembled that of ADHD or bipolar-associated mania, we treated both SH-WT and SH-RX mice with amphetamine, which attenuates the hyperactivity associated with ADHD while exacerbating the mania of bipolar disorder [38]. By amphetamine treatment, we could attenuate the hyperactivity of $\mathrm{SH}-$ WT and SH-RX mice significantly, whereas it induced the expected transient mania-like hyperactivity in controls (Fig. S10A,B). Accordingly, we conclude that the hyperactivity in SH-RX mice is consistent with an ADHD-like phenotype. Although the same neuronal circuits that increase hyperlocomotion may be affected by transgenic SHANK2A and SHANK2A(R462X) expression, the neuronal ensembles directing social behavior showed a reverse response towards novelty and social activities, when either SHANK2A or SHANK2A(R462X) were transgenically expressed. Since Dox-treated control littermates without the SHANK2A or SHANK2A(R462X) transgene expression served as respective controls, behavioral effects by the potential antiinflammatory activity or liver toxicity of Dox [39] can be excluded. In addition, in one of our previous studies, control mice with prenatal Dox treatment showed regular brain anatomy and solved several complex memory tasks [40].

\section{Information processing in the olfactory cortex is distorted bi-directionally in SH-WT and SH-RX mice}

The opposite social behavior of SH-RX and SH-WT mice suggested that neuronal responses to social novelty are 
A SH-WT (adult animals) $\square$ Ctrl. $\square$ SH-WT

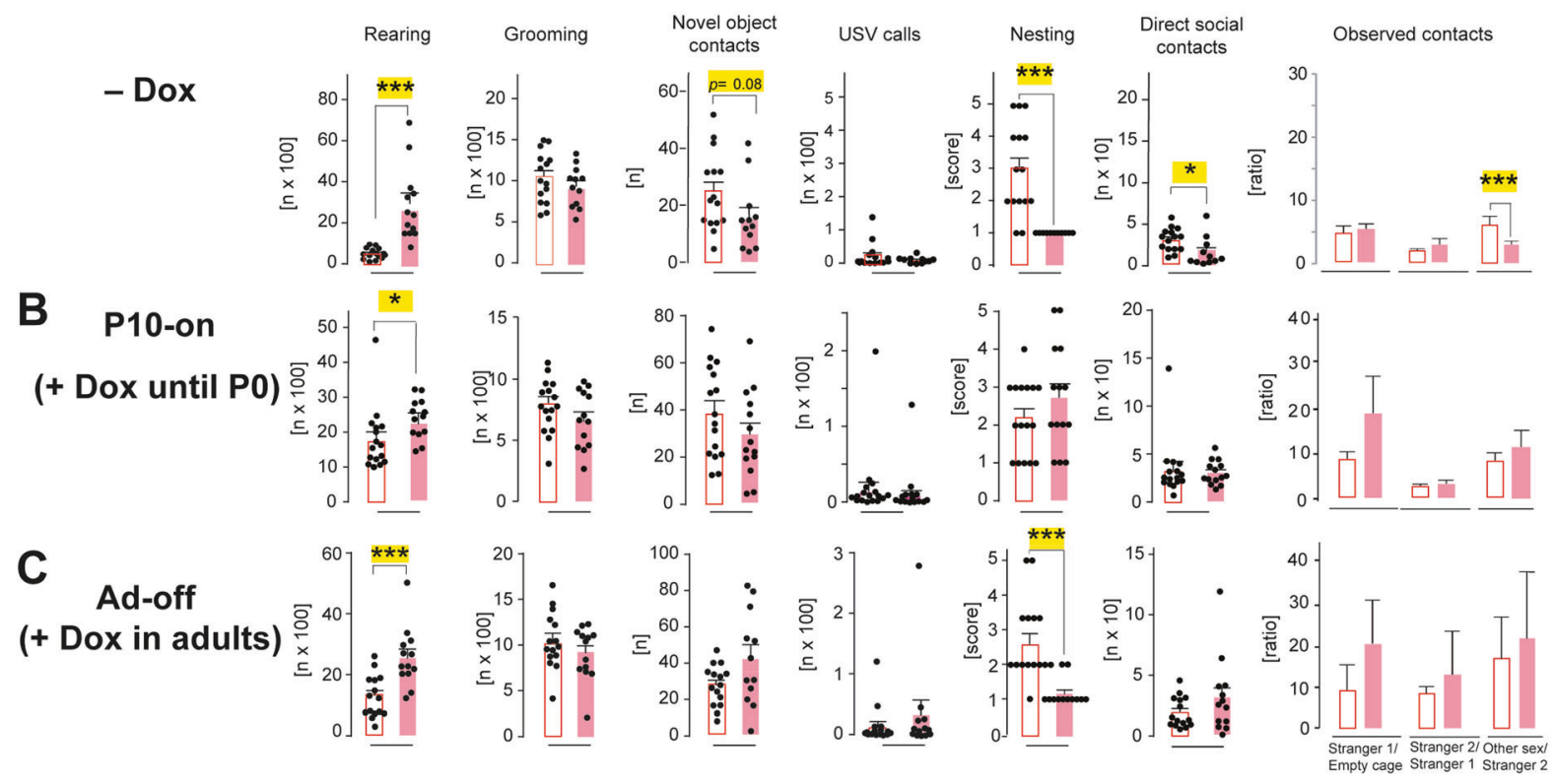

D SH-RX (adult animals) $\square$ Ctrl. $\square \mathrm{SH}-\mathrm{RX}$

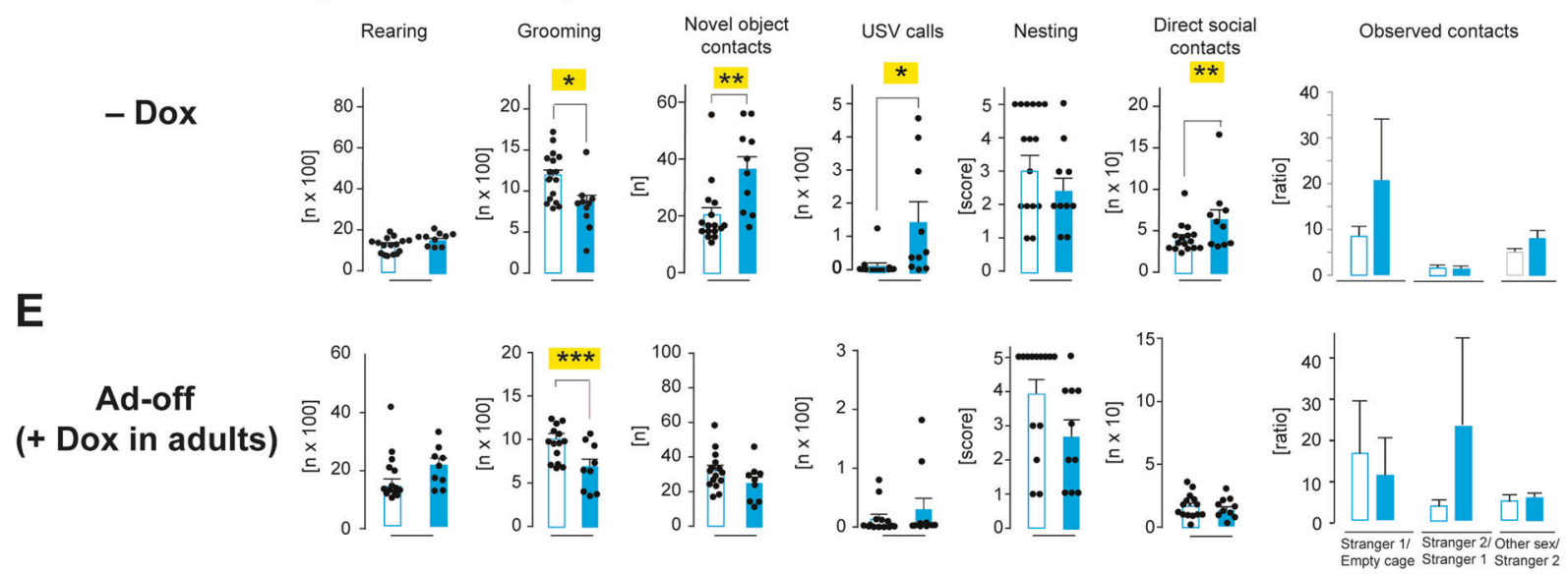

Fig. 4 Behavioral analysis of SH-WT and SH-RX mice revealed reversible social alterations. A Behavioral experiments of adult $\mathrm{SH}$ WT mice revealed increased repetitive rearing and normal selfgrooming in the LABORAS test, a borderline significant decrease in contacts in the novel object recognition test, a normal number of USV calls, nesting impairment, reduced direct social interaction, and reduced number of contacts in the third session of the three-chamber social test $(n=12$ SH-WT and 15 littermate control mice, 6-8 months). B Behavioral experiments of adult $\mathrm{SH}_{-}-\mathrm{WT}^{\mathrm{P} 10 \text {-on }}$ mice revealed a slight increase in repetitive rearing but no social impairment in the novel object recognition, nesting, direct social interaction, or three-chamber social tests $\left(n=14 \mathrm{SH}_{-\mathrm{WT}}{ }^{\mathrm{P} 10-\mathrm{on}}\right.$ and 16 and $\mathrm{Ctrl}^{\mathrm{P} 0 \text {-on }}$ mice, 4-6 months). C Behavioral experiments of adult SH-WT ${ }^{\text {Ad-off }}$ revealed increased repetitive rearing and reduced nesting behaviors but no social impairment in the novel object recognition, direct social

interaction, or three-chamber social tests $\left(n=12 \mathrm{SH}_{-\mathrm{WT}}{ }^{\text {Ad-off }}\right.$ and 15 Ctrl. ${ }^{\text {Ad-off }}$ mice, 5-8 months). D Behavioral analysis of adult SH-RX mice revealed normal rearing and reduced repetitive self-grooming in the LABORAS test with an enhancement of social interaction in the novel object recognition, USV, and direct social interaction tests. The nesting and three-chamber social test results were comparable to control mice $(n=10$ SH-RX and 16 littermate control mice, 6-8 months). E Behavioral analysis of adult SH-RX ${ }^{\text {Ad-off }}$ revealed a significantly reduced number of self-grooming but normal social interaction in the novel object recognition, nesting, USV, direct social interaction, and three-chamber social tests $\left(n=9 \mathrm{SH}-\mathrm{RX}^{\text {Ad-off }}\right.$ and 14 Ctrl. ${ }^{\text {Ad-off }}$ mice, 5-8 months). For all experiments, Two-way ANOVA was used $(* p \leq 0.05, * * p \leq 0.01, * * * p \leq 0.001)$. Error bars indicate the standard error of the mean (SEM).

differently affected in SH-RX and SH-WT mice. Rodents use olfaction for the primary sensing of social recognition and interaction by evaluating the incoming stream of multimodal sensory information. In this information stream, the

anterior olfactory nucleus (AON) — as part of primary olfactory cortices of the limbic system-controls statedependent coding during social interactions and is critical to both recognition and exploration of conspecifics [41-43]. 
Changes in sensory encoding in mouse models related to neurodevelopmental and neuropsychiatric disorders have been reported for higher-level regions such as the prefrontal cortex (e.g. [44]). It is not clear whether related changes occur already in the primary sensory cortices in mouse models for ASD.

$\mathrm{We}$, therefore, aimed to investigate the opposite social phenotype in SH-WT and SH-RX mice by examining the processing of pseudo-randomized presentation of seven molecularly similar odorant cues in single-unit recordings from the AON in awake, head-fixed mice (Fig. 5A). Specifically, we examined if the excitation/inhibition (E/I) balance in the network representations of olfactory stimuli was altered. We examined the sensory coding in the whole population consisting of both inhibited and excited AON neurons (Fig. S11A). The baseline sniffing frequency and the fraction of neurons with a response to at least one of the odorants were comparable between all genotypes (Fig. 5B, C). Also, the broadness of tuning, i.e., the number of odorants that evoked either an odor-excited or inhibited response in cell-odor pairs was comparable (Fig. S11B). However, the fraction of E/I odor responses differed among genotypes (Fig. 5D; Fig. S11B). Across all cell-odor pairs, the E/I ratio of odor responses was 2.0 in controls, 5.0 in SH-WT, and 1.4 in SH-RX mice (Fig. 5D). Thus, the stimulus excited activity of AON neurons was increased in SH-WT mice and decreased in SH-RX mice. The baseline firing ( $2 \mathrm{~s}$ before odor onset) across all units was decreased in SH-RX mice (Fig. 5E). AON neurons with odor-excited responses displayed a significantly increased baseline activity in SH-WT mice (Fig. 5E), indicating that the E/I ratio in the background noise is increased in SH-WT, while in SH-RX mice the network drive is globally reduced.

Importantly, also the AON unit responses to odors were differentially affected (Fig. S11C, D). The mean population odor-inhibited responses were smaller in the two transgenic genotypes compared to controls (Fig. 5F and Fig. S11E), and the peak-firing increases of task-excited responses were larger in SH-WT and SH-RX mice (Fig. 5G and Fig. S11E). While subtle bidirectional changes in the signal-tonoise ratio of stimulus-inhibited responses occurred in the two transgenic lines (Fig. 5H), the signal-to-noise for odorexcited responses in SH-WT remained unchanged (Fig. 5I) as the increased excitatory peak firing coincided with higher background noise compared to control mice. Yet, the signal-to-noise ratio of excitatory responses increased in SH-RX mice (Fig. 5I), due to their simultaneous increase in peak firing and decrease in background activity. In addition, in SH-RX mice, the peak width was narrower than in controls (Fig. S11F). Together these findings support a more precise sensory encoding in stimulus-excited olfactory cortex units of SH-RX mice, while SH-WT displayed an increased E/I balance of sensory coding in a system with more noise.

\section{Discussion}

Here we show that the brain-specific SHANK2A isoform has a direct effect on (I) daily life activities, anxiety, and social-related behaviors, (II) the molecular composition and plasticity of hippocampal synapses, (III) extrasynaptic functions, and (IV) the neuronal network in the anterior olfactory nucleus during development. The side-by-side comparative analysis of exogenous SHANK2A and the extrasynaptic SHANK2A(R462X) in excitatory forebrain neurons dissected the post- and extrasynaptic actions of SHANK2A at the molecular, physiological and behavioral level (Table 1A). In "Decipher V10.0" database (https:// decipher.sanger.ac.uk), several patients with ASD, intellectual disability and ADHD were reported with a duplication/triplication spanning the SHANK2 gene and in experimental systems, a Shank3 transgenic mouse model, modeling a human SHANK3 duplication, exhibited a mania-like phenotype and seizures consistent with synaptic excitatory/inhibitory imbalance [45]. Those data show that the disturbance of the balanced SHANK expression leads to neuropsychiatric phenotypes, emphasizing that the genetically controlled, endogenous SHANK expression is essential for the establishment and/ or expression of higher brain functions such as social and cognitive behaviors.

In our experimental approach, we achieve a 2.4-fold overexpression of the exogenous human SHANK2A in hippocampal neurons compared to the endogenous Shanks. Despite this overexpression, the hippocampal GluA1 levels and electrically-stimulated AMPAR current responses in CA1 pyramidal cells were not reduced. Instead, the SHANK2A overload in hippocampal excitatory neurons (i) increased the synaptic AMPAR response at apical CA1 dendrites by the incorporation of high-conductance $\mathrm{Ca}^{2+}$-permeable AMPAR and (ii) decreased their synaptic presence at basal dendrites (Table 1B). Thus, the developmental expression of the endogenous SHANK2 had a significant impact on the fundamental mechanism underlying synaptic maturation and the establishment of neural circuits during development. This SHANK2-mediated reorganization of selective AMPAR types in synapses finds support by results in hippocampal cultures. During synaptic maturation and plasticity, a $\mathrm{Zn}^{2+}$-dependent switch from GluA2-lacking $\left(\mathrm{Ca}^{2+}\right.$-permeable $)$ to GluA2-containing $\left(\mathrm{Ca}^{2+}\right.$-impermeable) AMPAR has been documented when Shank 2 and Shank3 cooperate [3]. Moreover, the involvement of GluA1 in neuropsychiatric disorders is well described [46, 47]. 
A

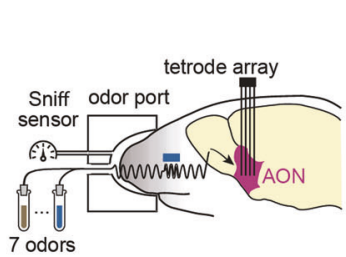

$B \square$ ctrl.

a SH-WT

a SH-RX

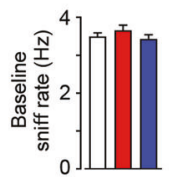

C Crtl. SH-WT SH-RX

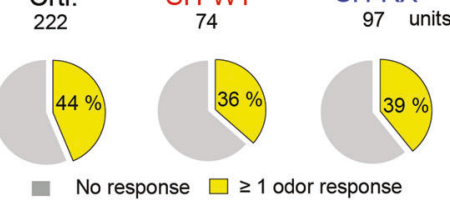

Ctrl.
1554

No response Excited

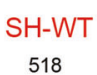

SH-RX 679 cell-odor pairs

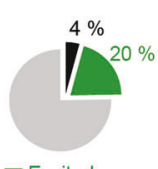

F

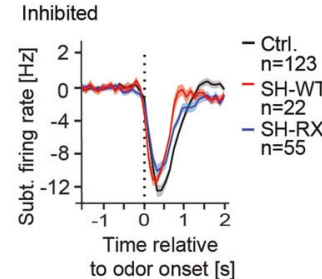

$\mathrm{H}$
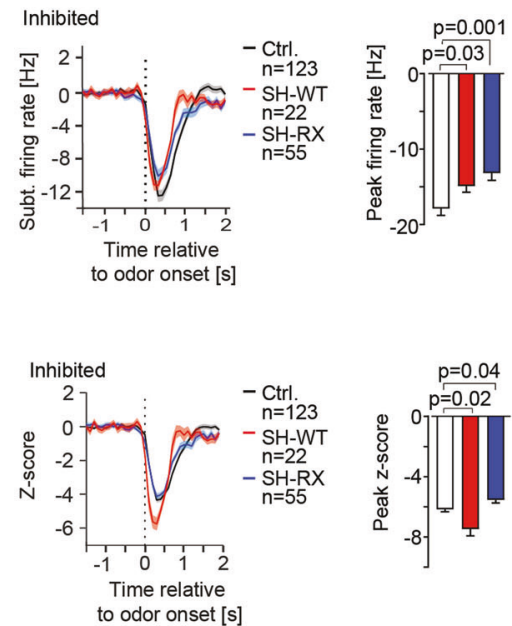

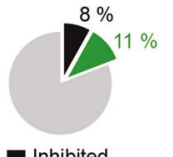

G
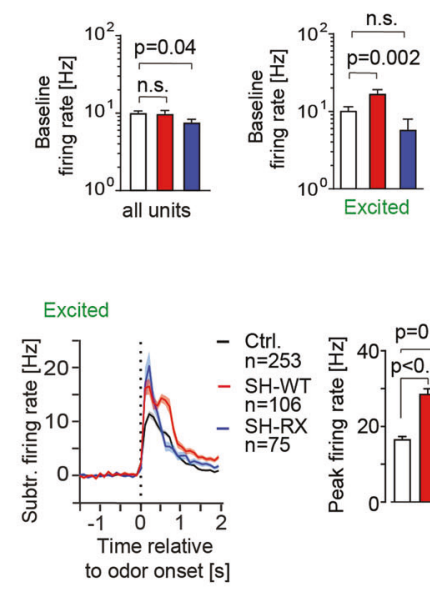

$\square$ Ctrl.

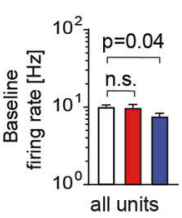

SH-WT
SH-RX 
SHANK2A(R462X) in excitatory neurons identified several proteins involved in transmitter release and axonal outgrowth which might explain the increase of basal dendrites. Among those synaptic enriched proteins, 23 proteins were also differentially expressed in the hippocampal synapticenriched proteome of thetransgenic SHANK2A, supporting an underestimated axonal function of SHANK2A and adding a functional explanation to the presynaptic/axonal localization of SHANK proteins [8, 9]. Our data suggest a direct presynaptic/axonal SHANK2 activity during early development, in addition to the post-to-presynapse SHANK2 communication, as postulated for the SHANK2modulated neuroligin/neurexin signaling [49]. Among the presynaptic differentially-regulated proteins, Plxnal and Plxna4 were less abundant. PLXNA1 and PLXNA4 are known to signal the binding of semaphorins in a shortdistance inhibitory manner. The Semaphorin/Plexin signaling has multiple functions in the regulation of both axonal and dendritic differentiation and branching [50-52] and may account for the increased branching of basal dendrites of CA1 neurons in presence of additional SHANK2A (R462X). Cortical neurons from induced pluripotent stem cells derived from ASD-affected donors with SHANK2 mutations showed an increase in dendritic length and complexity as well as synapse number [53]. Similarly, SHANK3 is known to participate in growth cone motility in developing neurons. Mutations in SHANK3 strongly affect the development and morphology of dendritic spines, reduce synaptic transmission in mature neurons, and also inhibit the effect of SHANK3 on growth cone motility [54].

It is well established that the SAM domains of SHANK proteins can bind to each other in a homomeric and heteromeric manner, enabling the SHANK proteins to multimerize tail-to-tail by a $\mathrm{Zn}^{2+}$-dependent mechanism $[55,56]$. The SAM domain is also essential for the localization of SHANK2 and SHANK3 proteins to the PSD [57]. As SHANK2A(R462X) lacks the SAM domain, SHANK2A (R462X) does not contribute to the postsynaptic scaffold and structural organization of postsynaptic receptors. Although we identified several axonal and presynaptic and putative downstream targets of SHANK2A(R462X), its direct presynaptic action remains speculative. The presence of the SH3 and PDZ domains might be sufficient to participate in the functional molecular organization of presynaptic or active zone proteins that contain PDZ and/or $\mathrm{SH} 3$ protein binding sites. The SHANK binding to one of the three SH3 domains of RIMBP2, might promote RIM to tether $\mathrm{Ca}^{2+}$ channels to the presynaptic active zone and thus to regulate $\mathrm{Ca}^{2+}$ secretion coupling [58] or it might participate in the priming of synaptic vesicles via the recruitment of Munc13-1 [59].

Similarly, the trafficking and function of AMPARs are controlled by auxiliary proteins and adaptor proteins. For instance, the interaction between the Rho-GAP protein Rich2 and SHANK3 can regulate AMPAR recycling and trafficking [60]. SHANK proteins could induce such modulations of the trafficking of GluA1-type $\left(\mathrm{Ca}^{2+}\right.$-permeable) AMPARs via the adaptor protein Rich or by the increasing synaptic accumulation of GluA2-type $\left(\mathrm{Ca}^{2+}\right.$-impermeable) AMPARs via the glutamate receptor-interacting protein [3]. Our unexpected finding that SHANK can regulate this trafficking on a subcellular level adds another layer of complexity to the field of activity-dependent AMPAR modulation that includes receptor trafficking and AMPAR auxiliary subunits [61, 62].

We cannot exclude that some of the observed axonal/ presynaptic SHANK2A-mediated alterations were induced by retrograde signaling. However, since the transgenic extrasynaptic SHANK2A(R462X) mutant has an identical effect on axonal proteins, this is very unlikely; a bifunctional role of (i) the PSD-localized SHANK2A and (ii) the cytoplasmic SHANK2A seems to be most likely. Whether these dual pre- and postsynaptic functions are specific to SHANK2A and only important during development of the nervous system and maturation of axons and dendrites remains to be resolved. It is likely that some of the molecular effects we observed are not induced directly by SHANK2A but are secondary consequences of impaired or inhibited neuronal maturation induced by the transgenic SHANK2A variants in SH-WT and SH-RX mice.

Although the SHANK2A(R462X)-associated ADHDlike hyperactivity, anxiety, and impaired daily life activities, and the increased social and reduced repetitive behaviors were diametrically opposed to the SHANK2A-induced poor social interaction and enhanced repetitive behavior [5], all social behavioral impairments of adult SH-WT mice could be attributed to the unbalanced SHANK2A expression during the development in excitatory neurons. The expression in the inhibitory granular cells of the olfactory bulb did not alter the odor recognition. However, the hyperactivity and the opposed response of SH-WT and SH-RX mice to amphetamine, when compared to control animals, was most likely attributed to the transgenic SHANK2A or SHANK2A (R462X) expression in MSN in the striatum, even if alterations of striatal circuits might also have an effect on typical ASD-like behaviors [63, 64].

Balancing the SHANK2A expression during late postnatal development and in adults attenuated the hyperactivity, anxiety, and food burrowing and normalized the social impairment. This finding underlines the strong developmental component in genetically inherited ASD. It also suggests that after postnatal development, SHANK1 and SHANK3 dominate the SHANK scaffold in the mature nervous system, as recently evidenced by the very pronounced neurophysiological phenotype of Shank1/3 double KO mice and the early death of $60 \%$ of these mice within 
the first five weeks of life [65]. It also excludes a major direct contribution of transgenic chromosome 12 insertions [23] of the Camk2a-tTA transgene in our behavioral analysis. By normalizing the SHANK2 levels in adults, the sociability could be normalized. Similar to the genetic rescue of Shank3 KO mice [36], only social and novelty interactions were restored, demonstrating that the neuronal circuits for social responses are not permanent and that the SHANK scaffold in neuronal circuits for neuronal circuits can be remodeled in adults genetically or by pharmacological modulation of the synaptic transmission [35].

The very different impact of the postsynaptic and isolated presynaptic SHANK2A activity on neuronal network activity of SH-WT and SH-RX mice was directly correlated with differences in odor encoding in the olfactory cortex. The exogenous SHANK2A promoted the formation of stimulus-excited units in the AON as recognized by the increased excitability, in the absence and presence of an odor stimulus. In contrast, SHANK2A(R462X) reduced the basal excitability signaling, improved the signal-to-noise ratio of odor cues with direct consequences for the social activity. Thus, the more precise sensory encoding in stimulus-excited olfactory cortex units of SH-RX mice, and the increased E/I balance of sensory coding in a system with more noise is in line with the opposing social behavior in SH-RX and in SH-WT mice. It supports the recent finding of the different c-Fos expression and the opposing social behavior of a Shank2 and a Shank3 KO mouse line. This analysis demonstrated that the social behavior is critically determined by the balanced excitation/inhibition ratios in a subset of brain regions that collectively contribute to the abnormalities in social dominance and social cooperation that is differently affected in Shank2 and Shank3 KO mice [66].

In summary, our study has revealed that SHANK2A modulates the proteomic composition and plasticity of excitatory synapses during pre- and postnatal development when endogenous SHANK2 expression reaches its peak [67]. In the presynapse, the SHANK2A-regulated proteins are well-known synaptic and axonal organizers. In the postsynapse, $\mathrm{Ca}^{2+}$-permeable AMPARs were reorganized at synapses of basal and apical dendrites, which modulated their plasticity. In excitatory olfactory cortex units, SHANK2A-modulated signaling was a critical component of social behavior. Increased excitatory noise in the AON units by exogenous SHANK2A was associated with decreased social interaction. Improving the precision of excitatory cortical coding in the AON units by selective presynaptic SHANK2A alterations, in turn, came with increased social interests. SHANK2A exerted its effect on the social nervous system during pre- and early postnatal development only. Therefore, we conclude that the SHANK2A postsynaptic modifications are accompanied by less pronounced but cooperative presynaptic modifications that can fine-tune the synaptic efficiency and neuronal connectivity.

\section{Materials and methods}

\section{Ethical statement}

Mice maintenance and procedures were performed according to the animal welfare guidelines of the Max Planck Society and the Heidelberg University. Transgenic animals were generated by pronucleus injection into fertilized C57BL6/N oocytes (license number AZ: 35-9185.81/G219/11; Governmental Council Karlsruhe). In vivo recordings were performed under the license (AZ: 35-9181.81/G239/14) to W. Kelsch. All behavioral experiments were performed at the Interdisciplinary Neurobehavioral Core Facility of Heidelberg University (INBC) under the license (AZ: 35-9185.81/G-100/16) to C. Pitzer. SH-WT mice are bred and housed under the license (AZ: 359181.81/G-328/19) of the Regierungspräsidium Karlsruhe due to their reduced body weight and increased mortality several weeks after birth. Mice killed for postmortem analysis were registered at the IBF/Heidelberg University (T61/15, T-51/17 and T48/19).

\section{Animals}

For the generation of the conditional expression of SHANK2A in mice, we used the well-established doxycycline-controlled expression system [68-70]. The tTA responder transgenic mice were generated by the pronuclear injection of C57BL/6 blastocytes with either SHANK2A or SHANK2A(R462X) plasmid fragments that encode the bidirectional tetracycline-responsive promoter element (Ptetbi) [71] controlling the expression of the nuclear-localized $\beta$-galactosidase (nLacZ) on one side and fusion transcript composed of green fluorescent protein variant (Venus), fused via the ribosomal skipping sequence T2A to either SHANK2A or SHANK2A(R462X) on the other side (Fig. 1A). To activate the expression of the tTA-dependent genes and direct it towards the forebrain neurons, the responder transgenic mice were crossed with $T g$ Camk2a-tTA mice (activator mice) in a C57BL/6N background that expresses the dox-sensitive transactivator (tTA) under the control of an $8.5 \mathrm{~kb}$ fragment of the $\alpha \mathrm{CaMKII}$ promoter [72], which led to the generation and selection of $T g^{S H A N K 2 A / T A}$ and $T g^{S H A N K 2 A(R 462 X) / t T A}$ double transgenic mice with similar nLacZ expression levels (Fig. 1A, C). These lines, expressing tTA in addition to either SHANK2A or SHANK2(R462X), are named $T g^{\text {SHANK2A }}$ (SH-WT) and $T g^{\operatorname{SHANK2A(R462X)}}$ (SH-RX), respectively. Littermate mice 
with a single transgene, either the tTA-activator or the responder transgene, were included as control littermates together with non-transgenic littermate control mice (Ctrl.). For adult SH-WT as well as SH-RX mice, the expression of either SHANK2A or SHANK2A(R462X) along with other reporter proteins is strictly dependent on the synthetic transcription factor, the "tetracycline transactivator" (tTA). In adult Dox naïve mice, the expression of transgenes can be found in the excitatory neurons of the hippocampus and cortex [73], inhibitory granular cells in the olfactory bulb [68], and inhibitory MSN in the dorsal striatum [74] (Fig. 1C; Fig. S1-S3). In our previous experiment using the Camk2a-tTA expression system, we noticed already in mouse embryos and at P0 a substantial expression of functionally active Camk2a-controlled tTA transgenes $[68,73]$ (Fig. S3), which is also detectable by the $\beta$-galactosidase, Venus, and transgenic SHANK2 expression in brain extracts of SH-WT mice (Fig. 1G). After the Dox clearance in the newborn pups, the Camk2a-tTA-controlled $\beta$-galactosidase, Venus and SHANK2A reached a substantial expression level 3 weeks after birth (Fig. 1G). In contrast to Tetracycline, which normally leads to cleft palate and congenital abnormalities, there is no evidence that Dox is teratogenic [75]. Nevertheless, it is well documented that Dox has anti-inflammatory effects (e.g., [76, 77]). Therefore, in all Dox experiments, littermates treated with Dox were used as control mice to discard any effect possibly induced by the Dox treatment. Mice were housed in the IBF at Heidelberg University under a $12 \mathrm{~h}$ light-dark cycle and given access to water and food ad libitum. One week before the behavioral analysis, the mice were transferred to $t \sim$ he INBC without changing the light-dark cycle for the animals. Dox treatment was performed at the INBC. To stop the transgene expression in $T g^{S H A N K 2 A / T A}$ and $\operatorname{Tg}^{\text {SHANK2A(R462X/TA) }}$ adult mice, Dox (Sigma-Aldrich) at a concentration of $2 \mathrm{~g} / \mathrm{l}$, supplemented with $5 \%$ sucrose, was dissolved in water and provided to adult mice in lightprotected bottles. To avoid tTA-controlled transgene expression during neurodevelopment in offspring, $50 \mathrm{mg} / \mathrm{l}$ dox, supplemented with $5 \%$ sucrose, was provided in water to pregnant mice until labor.

\section{Eosin/X-Gal staining}

Enzymatic activity of $\beta$-galactosidase expression was assessed by Eosin/X-Gal staining following the standard protocol with modifications. Brain slices were washed in PBS for $20 \mathrm{~min}$ and then incubated in LacZ solution $(0.5 \mathrm{M}$ $\left.\mathrm{K}_{4} \mathrm{Fe}(\mathrm{CN})\right)_{6}, \quad 0.5 \mathrm{M} \quad \mathrm{K}_{3} \mathrm{Fe}(\mathrm{CN})_{6}, \quad 0.2 \mathrm{M} \quad \mathrm{MgCl}_{2}, \quad \mathrm{X}$-Gal $20 \mathrm{mg} / \mathrm{ml}$ in PBS) for $2 \mathrm{~h}$ at $37^{\circ} \mathrm{C}$. The slices were then washed three times with $1 \times$ PBS and shortly washed in $10 \mathrm{mM}$ TRIS (pH 7.6) before being mounted onto glass slides. After an overnight dry session in RT, 0.5\% Eosin solution was used as a counterstain, and slides were shortly washed in demineralized water, 70\% EtOH, $80 \% \mathrm{EtOH}$, and $100 \% \mathrm{EtOH}$, respectively. After drying, slides were washed in Xylol, and drops of Eukitt were put onto each slice. As the last step, the coverslips were placed onto the slices and the slides were left to air dry at RT for polymerization.

\section{Immunoblot analysis}

All steps for total protein lysate preparation from different brain tissues were performed at $4{ }^{\circ} \mathrm{C}$. Cortex, hippocampus, olfactory bulb, and cerebellum of the mouse brain were collected and homogenized in ice-cold buffer $(25 \mathrm{mM}$ HEPES, pH 7.4) containing a protease inhibitor cocktail (Complete, Roche, Pharma AG). After $5 \mathrm{~min}$ of centrifugation at $2000 \mathrm{rpm}$, the supernatant containing the total amount of proteins was collected. Protein concentration was determined with the BCA protein assay kit (Pierce). Ten $\mathrm{mg}$ of protein were separated by SDS-PAGE (8-12\% separating and $4 \%$ stacking gels) and transferred to Amersham ${ }^{\mathrm{TM}}$ nitrocellulose membranes Protran $(\mathrm{R})$ (Sigma-Aldrich). Membranes were probed with the antibodies which are given in Table S4 together with the dilution used. Chemiluminescence was developed using a detection reagent (GE Healthcare, Amersham ${ }^{\mathrm{TM}}$, ECLTM Prime Western Blotting Detection Regent, RPN2232) and visualized with the Fujifilm LAS-3000 Luminescent Image Analyzer (Object No.: B00000623) using the Image Reader LAS-3000 software and quantified using ImageJ software. As exemplified for the anti-human SHANK2, the anti-beta-tubulin antibody and anti-Venus antibody (Fig. S2C), the quality of the antibodies was tested before usage.

\section{Messenger RNA Expression nCounter analysis}

Total RNA from mice hippocampi was extracted with TRIzol (Invitrogen) and the gene expression profile was investigated at the nCounter Core Facility, Heidelberg, using the nCounter Dx analysis system GEN1 (NanoString Technologies). A customized elements code set with 12 target genes and 6 reference genes was applied (for probe design, see Table S5). The detailed workflow is described at https://www.nanostring. com/support/product-support/supportworkflow. Background correction and normalization of data were performed using the nSolver Analysis Software 3.0 (NanoString Technologies). Positive control and reference gene normalization were performed according to the gene expression analysis guideline from NanoString Technologies (https://www.nanostring. com/application/files/7715/1251/5220/Gene_Expression_Da ta_Analysis_Guidelines.pdf; accessed June 2018). All the chosen reference genes Gapdh, Sdha, Hprtl Gpil, Hspdl, and $P g k 1$ showed a stable expression and were selected for normalization based on the geNorm method [78]. The unit of 
measurement is "codeset counts". The codeset counts of the control mice were set to 1 . Original data are accessible at https://edmond.mpdl.mpg.de under (Collections: Sprengel).

\section{Electrophysiological analysis}

Transverse hippocampal $300 \mu \mathrm{m}$ slices were prepared from the brains of mice at the age of 4-7 weeks. Mice were killed by cervical dislocation. The slicing chamber contained an oxygenated ice-cold solution composed of (in mM): $K$-Gluconate, $140 ; N$-(2-hydroxyethyl) piperazine- $N N^{\prime}$-ethanesulfonic acid (HEPES), 10; Na-Gluconate, 15; ethylene glycol-bis (2-aminoethyl)- $N, N, N^{\prime}, N^{\prime}$-tetraacetic acid, 0.2 ; and $\mathrm{NaCl}, 4(\mathrm{pH}$ 7.2). Slices were incubated for $30 \mathrm{~min}$ at $35^{\circ} \mathrm{C}$ before being stored at room temperature in artificial CSF (ACSF) containing (in $\mathrm{mM}$ ): $\mathrm{NaCl}, 125 ; \mathrm{NaHCO}_{3}, 25 ; \mathrm{KCl}, 2.5 ; \mathrm{NaH}_{2} \mathrm{PO}_{4}$, 1.25; $\mathrm{MgCl}_{2}, 1 ; \mathrm{CaCl}_{2}, 2$; and D-glucose, 25; bubbled with $95 \% \mathrm{O}_{2}$ and $5 \% \mathrm{CO}_{2}$. During experiments, slices were continuously perfused with the same ACSF. Patch electrodes were pulled from hard borosilicate capillary glass (Sutter Instruments flaming/brown micropipette puller). Electrodes for the postsynaptic pyramidal cells were filled with a solution consisting of (in mM): Cs-gluconate, 100; $\mathrm{CsCl}, 40$; HEPES, 10; $\mathrm{NaCl}, 8$; MgATP, 4; MgGTP, 0.3; phosphocreatine, $10(\mathrm{pH}$ 7.3 with $\mathrm{CsOH}$ ).

CA1 pyramidal cells were visually identified using IRvideo microscopy. Whole-cell recordings from these neurons were taken at room temperature $\left(23-25^{\circ} \mathrm{C}\right)$ in voltage-clamp mode using a HEKA EPC-7 amplifier (List Elektronik) with a sampling rate of $100 \mu$ s and filtered at $3 \mathrm{kHz}$. EPSCs were evoked from two independent inputs, basal and apical dendrites, with two patch pipettes as stimulating electrodes located in str. oriens and str. radiatum, respectively. The two stimulus pipettes were $>200 \mu \mathrm{m}$ apart, located below and above the soma of a CA1 pyramidal cell. All measurements were at $-70 \mathrm{mV}$ membrane potential.

The AMPA/NMDA current ratios were measured in $\mathrm{Mg}^{2+}$-free ACSF. AMPA- and NMDA-mediated EPSCs were pharmacologically isolated by sequential bath application of D-APV $(200 \mu \mathrm{M}$ 2-amino-5-phosphonovaleric acid; Sigma-Aldrich) and NBQX (10 $\mu$ M; Sigma Aldrich), respectively. First, the compound AMPAR and NMDARmediated current were recorded in $\mathrm{Mg}^{2+}$-free ASCF. After collecting at least 100 sweeps, the AMPA-mediated component was blocked by the application of NBQX. Then, additional 100 sweeps of the putative NMDA-mediated currents were collected and the NMDA nature was confirmed by a subsequent application of D-APV. The AMPAmediated component was then obtained by subtracting the averaged NMDA-mediated currents from the averaged compound responses. For subsequent analysis, the mean amplitude of the AMPA currents was normalized to the level of the amplitude of the NMDAR EPSCs. When specified, $200 \mu \mathrm{M}$ 1-naphthyl acetyl spermine (Naspm) (Tocris) was used to block $\mathrm{Ca}^{2+}$-permeable AMPARs [79]. In LTP experiments the control pathway was measured by stimulating synapses of the basal dendrites when apical dendrite input was potentiated and vice versa: the input in the $s t r$. radiatum was used as a control pathway when the paired pathway was input to synapses of the basal dendrites. LTP was evoked and recorded by voltage-clamping the membrane potential of the postsynaptic pyramidal cell to $0 \mathrm{mV}$ for 3 min while stimulating the paired pathway every $1.5 \mathrm{~s}$ [80]. The measured amplitudes were normalized to the mean EPSCs before pairing. The NMDAR dependence was tested in the presence of $100 \mu \mathrm{M}$ D-APV.

\section{Biocytin labeling and Sholl analysis}

After electrophysiological analysis, the slices having biocytin-labeled neurons (internal patch solution contained $0.1 \% \mathrm{w} / \mathrm{v}$ biocytin (Biomol)) after electrophysiological analysis were treated with $1 \% \mathrm{H}_{2} \mathrm{O}_{2}$ for 10 min to quench endogenous oxidase activity. The slices were then permeabilized using $0.2 \%$ Triton in PBS for $2 \mathrm{~h}$ and incubated in Vectastain ABC complex for another $2 \mathrm{~h}$. The slices were then washed twice with Tris $20 \mathrm{mM}$ PH 7.6 for $10 \mathrm{~min}$ and incubated in DAB solution for $20 \mathrm{~min}$ in the dark. At last, $0.01 \% \mathrm{H}_{2} \mathrm{O}_{2}$ solution was added to the well-containing slices in $\mathrm{DAB}$ solution and the reaction stopped by transferring the slices to a well with Tris $20 \mathrm{mM} \mathrm{PH} \mathrm{7.6.} \mathrm{Z-stack}$ images of $0.1 \mu \mathrm{M}$ intervals were taken using the Leica DMI4000 B microscope and Leica application suite advanced fluorescence software. Sholl analysis was completed in Fiji (ImageJ 2.0.0-rc-69/1.52i). Basal dendrites were traced and morphology was analyzed using the Simple Neurite Tracer (v.3.1.3 plugin) to obtain measurements for total dendrite length and Sholl analysis (3.7.4 2018-09-25) with $10 \mu \mathrm{m}$ radius. For the representation of pictures in Fig. $3 \mathrm{H}$, dendrites reconstruction was performed using Imaris $\times 64$ 9.0.2 software (RRID:SCR_007370).

\section{Mass spectrometry (MS) proteomic analysis}

The pre- and postsynaptic protein-containing synapse-enriched fractions (P2 fractions) were prepared as previously described [81]. In brief, hippocampi from $7 \mathrm{SH}-\mathrm{WT}, 7 \mathrm{SH}-$ $\mathrm{RX}$, and 14 control mice (both non-transgenic and mice with a single transgene) were dissected and stored at $-80^{\circ} \mathrm{C}$. Each tissue sample was homogenized (in $5 \mathrm{mM}$ HEPES, $\mathrm{pH}$ 7.4, $0.32 \mathrm{M}$ sucrose, protease inhibitor cocktail (Roche)) and centrifuged at $1000 \times g$ for $10 \mathrm{~min}$ at $4{ }^{\circ} \mathrm{C}$. The supernatant was centrifuged at $20,000 \times g$ for $30 \mathrm{~min}$ at $4{ }^{\circ} \mathrm{C}$, and the resulting pellets ( $\mathrm{P} 2$ fractions) were processed for MS analysis. 
In-solution digestion of proteins was performed by using the filter-aided sample preparation protocol [82]. Briefly, $30 \mu \mathrm{g}$ of each sample were mixed with $75 \mu \mathrm{l} 2 \%$ SDS, $1 \mathrm{mM}$ Tris (2-carboxyethyl)phosphine and incubated at $55^{\circ} \mathrm{C}$ for $1 \mathrm{~h}$. Cysteines were blocked with $0.5 \mu \mathrm{l} 200 \mathrm{mM}$ methyl methanethiosulfonate and $200 \mu \mathrm{l} 8 \mathrm{M}$ Urea in Tris pH 8.8 were added. Samples were transferred to Microcon-30 filter tubes (Millipore) and centrifuged at $14,000 \times g$ for $15 \mathrm{~min}$ at RT. Samples were washed four times with $200 \mu \mathrm{L} 8 \mathrm{M}$ urea and, subsequently, four times with $200 \mu \mathrm{l} 50 \mathrm{mM}$ ammonium bicarbonate. Proteins were digested with $0.7 \mu \mathrm{g}$ Trypsin/Lys-C Mix (MS grade, Promega) in $50 \mathrm{mM}$ ammonium bicarbonate overnight at $37^{\circ} \mathrm{C}$. Peptides were recovered by an additional wash with $200 \mu \mathrm{l} 50 \mathrm{mM}$ ammonium bicarbonate, dried in a SpeedVac, and stored at $-20^{\circ} \mathrm{C}$ until used.

For SWATH-MS, peptides were subjected to micro LC MS/MS using an Ultimate 3000 LC system (Dionex, Thermo Scientific). Peptides were trapped in a $5 \mathrm{~mm}$ Pepmap $100 \mathrm{C} 18$ column $(300 \mu \mathrm{m}$ i.d., $5 \mu \mathrm{m}$ particle size, Dionex $)$ and fractionated in a $200 \mathrm{~mm}$ Alltima C18 column (100 $\mu \mathrm{m}$ i.d., $3 \mu \mathrm{m}$ particle size). The concentration of acetonitrile in $0.1 \%$ formic acid was increased linearly from 5 to $18 \%$ in $88 \mathrm{~min}$, to $25 \%$ at $98 \mathrm{~min}, 40 \%$ at $108 \mathrm{~min}$, and to $90 \%$ in $2 \mathrm{~min}$, at a flow rate of $5 \mu \mathrm{l} / \mathrm{min}$. Peptides were electro-sprayed into the TripleTOF 5600 mass spectrometer (Sciex), with a microspray needle voltage of $5500 \mathrm{~V}$. Each SWATH cycle consisted of a parent ion scan of $150 \mathrm{msec}$ and $8 \mathrm{Da}$ SWATH windows ( $80 \mathrm{msec}$ scan time), throughout a $450-770 \mathrm{~m} / \mathrm{z}$ mass range, as described by [83]. The orignial data of the analysis are available in Supplementary Data 1.

The data were analyzed using Spectronaut (Version 12.0.20491.4.23092) with a spectral library previously generated from synaptosomal preparations by data-dependent acquisition [84]. Cross-run normalization was enabled and the peptide abundances were exported for further processing using $\mathrm{R}$ language. Limma $\mathrm{R}$ package was used to Loess normalize protein abundance ("normalizeCyclicLoess" function) $[85,86]$. Only high confidence peptides were used for protein quantification by setting a threshold of $Q$-value of $\leq 10$ ${ }^{-3}$ (allowing one outlier within each group), while the standard was $10^{-2}$. We opted for this more stringent peptide selection to increase the reliability in the quantification of all proteins, while at the same time, including proteins covered by one peptide (Fig. S5). Protein abundances were obtained by the summation of the normalized peak area of their respective peptides. Identifying differentially expressed proteins is a task in proteomic studies commonly carried out simply using t-tests. In this manuscript, we demonstrated how better results can be achieved by using moderated t-statistics from the empirical Bayes procedure Limma. Statistical analysis was performed at the protein level.

\section{Pathway analysis}

The pathway analysis was performed at the internet portals Synaptic Gene Ontologies, SynGo (https://www.syngoporta 1.org) [20] and ConsensusPathDB-mouse, CPDB (http:// cpdb.molgen.mpg.de/MCPDB) using the integrated databases [19].

\section{Behavioral assays}

One week prior to the start of the behavioral experiments, the mice were single-housed in an animal room with constant temperature $\left(22^{\circ} \mathrm{C}\right)$ and ad libitum access to water and food. They were handled 5 days extensively (10 min per mouse a day) to reduce anxiety and to get acquainted with the testing environment. Behavioral studies were performed during the light phase between 9 a.m. and 6 p.m., except for nesting and burrowing tests. The experiments were performed on 4-8 months old adult male and female mice. Littermate mice with a single transgene (either activator or responder transgene) were included in the control population along with non-transgenic control mice. All behavioral tasks were performed in a blind manner.

The behavioral studies were performed in the following order: LABORAS, open field, dark-light box, burrowing, nesting, three-chamber social, novel object recognition, neophobia, and direct social interaction. Before experiments and between different trials, all equipment was cleaned and wiped with $70 \%$ ethanol and allowed to evaporate completely. Automatic video-taped tracking tests (Sygnis Tracker, Sygnis) were used.

\section{LABORAS}

The LABORAS test (Laboratory Animal Behavior Observation Registration and Analysis System) is an advanced and non-invasive system that automatically recognizes several different behaviors of mice by analysis of the forces that are induced by their movement (METRIS). Each mouse was tested individually in a cage on the system for $24 \mathrm{~h}$ to detect the duration and frequency of locomotion, immobility, climbing, rearing, self-grooming, drinking, and eating.

\section{The nesting test}

The mouse was placed in a new home cage at 5 p.m. with cotton nesting material. After the nest was built it was checked the next day at 7 a.m., and its quality was assessed with a complexity score from 1 (no nest) to 5 (complex nest with a wall surrounding the mouse) [87]. 
Table 1 A. Effects of pre-and postsynaptic localized SHANK2A and SHANK2A(R462X) overexpression in transgenic mice. B. Schematic representations of the distribution of synapses enriched for $\mathrm{Ca}^{2+}$-permeable (in green; high conductance) or $\mathrm{Ca}^{2+}$-impermeable (in orange; low conductance) AMPARs in apical and basal dendrites of hippocampal CA1 pyramidal cells in wild-type, SHANK2A overexpressing (SH-WT) and SHANK2A(R462X) overexpressing (SH-RX) mice.

A

\begin{tabular}{|c|c|c|}
\hline Transgenic mice & SH-WT & SH-RX \\
\hline $\begin{array}{c}\text { Localisation of Transgenic } \\
\text { SHANK2A }\end{array}$ & Synaptic & Extra-Synaptic \\
\hline Phenotype & ASD-like & ADHD-like \\
\hline $\begin{array}{c}\text { Hyperactivity } \\
\text { Anxiety } \\
\text { Increased repetitive }\end{array}$ & $\begin{array}{c}\text { Hyperactivity } \\
\text { Anxiety } \\
\text { Decreased repetitive }\end{array}$ \\
\hline Reversible Behavior & Reduced Sociability & Increased Sociability \\
\hline $\begin{array}{c}\text { Hippocampal Subcellular Synaptic } \\
\text { Plasticity }\end{array}$ & Altered Plasticity & $\begin{array}{c}\text { Increased Dendritic } \\
\text { Sprouting }\end{array}$ \\
\hline $\begin{array}{c}\text { Hippocampal Synaptic } \\
\text { Proteins }\end{array}$ & Altered in Pre-and Postsynapse & $\begin{array}{c}\text { Altered in Presynapse } \\
\text { Odor Recognition }\end{array}$ \\
\hline
\end{tabular}

B

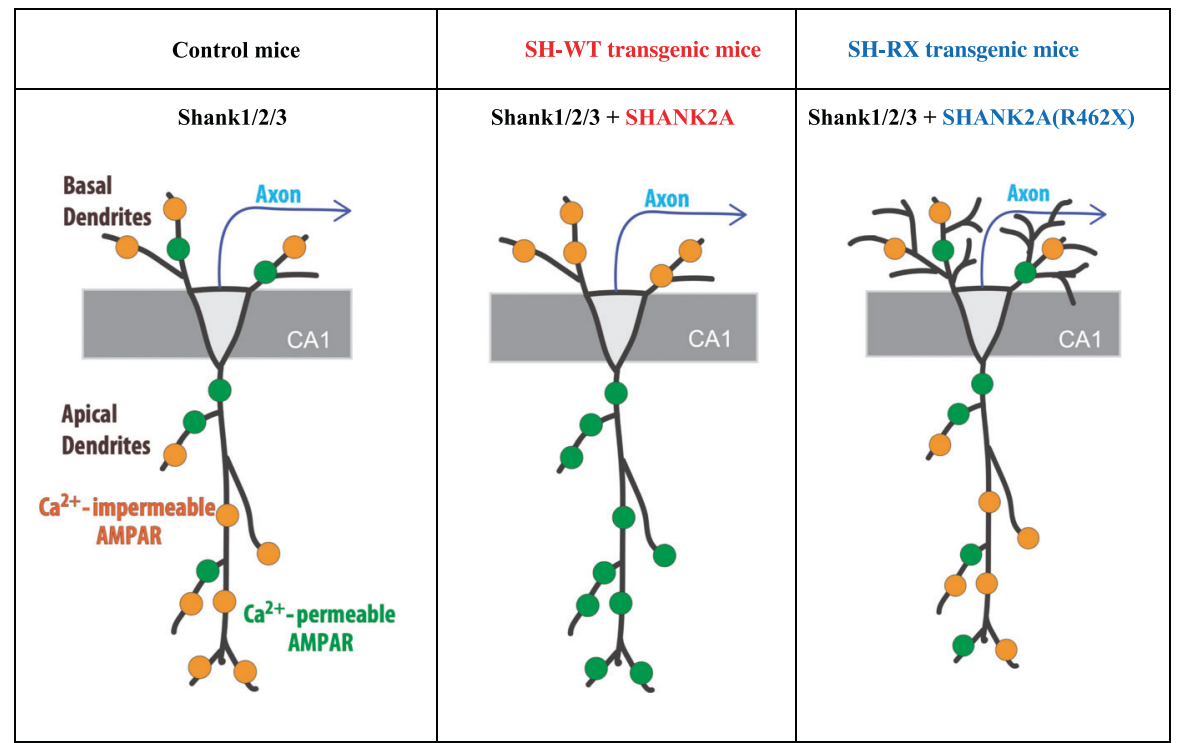

\section{The three-chamber social test}

The test was performed as described previously [88], with some modifications. A social interaction box (Harvard Apparatus) divided into three compartments was used. The social arena included a transparent box $(42 \times 60 \mathrm{~cm})$ with two transparent sliding doors that divided the left, right, and center chambers $(42 \times 20 \mathrm{~cm})$. In the first $5 \mathrm{~min}$ session, the tested mouse was placed in the central chamber with open sliding doors to offer access to the other two chambers for habituation. In the second session, an empty cylindrical cage and another cylindrical cage housing an unfamiliar C57BL/6N mouse of the same sex and age as the tested mouse were located in the corners of the left and right chambers. The tested mouse was placed in the central chamber and allowed to explore the arena for $5 \mathrm{~min}$. Once this session was completed, another unfamiliar C57BL/6 N mouse (novel mouse) with the same sex and age as the tested mouse was put in the empty cylindrical cage. The tested mouse was then allowed to explore the arena for $5 \mathrm{~min}$. In the fourth session, the mouse in the cylindrical cage from session 2 was replaced by an unfamiliar C57BL/ $6 \mathrm{~N}$ mouse of the opposite sex. The tested mouse was then allowed to explore the arena for $5 \mathrm{~min}$. The location of the cages was alternated between tests. The number of observed contacts of the tested mice was counted manually.

\section{Novel object recognition}

Each mouse was placed in the corner of a new arena $(40 \times$ $40 \times 40 \mathrm{~cm}$ ) and allowed to explore the arena for $5 \mathrm{~min}$. The mouse was then returned to its home cage for $1 \mathrm{~min}$ and 
reintroduced to the arena for another 5 min with a fixed novel object (cube) in the center. The number of contacts with the object was counted manually.

\section{Direct social interaction test}

The test mouse was placed in a white acrylic open-field box $(40 \times 40 \times 40 \mathrm{~cm})$. After $1 \mathrm{~min}$, a same-sex, similar-age, unfamiliar C57BL/6 $\mathrm{N}$ mouse was added to the arena. The number of contacts between the tested and the unfamiliar mouse was counted manually for $5 \mathrm{~min}$.

\section{Ultrasonic vocalizations (USV)}

USV was recorded during the direct social interaction tests. USV recording (from 0 to $100 \mathrm{kHz}$ ) and analysis were conducted with the equipment and software from Avisoft Bioacoustics (Berlin) as described [89]. Acoustic signals were recorded, amplified, and digitized at $250 \mathrm{kHz}$ with a 16-bit resolution by the Ultrasound Gate $416 \mathrm{Hb}$ USB audio device, and ultrasonic condenser microphones CM16/ CMPQ were placed $30 \mathrm{~cm}$ above the testing area.

\section{In vivo recordings}

Recordings were performed from the pars centralis of the anterior olfactory nucleus (AON) in mlib toolbox6 control, 4 SH-WT, and 6 SH-RX mice. Each custom-built recording array contained up to 16 tetrodes. Tetrode tips were goldplated to achieve a lower recording impedance (target: 300 $\mathrm{kOhm}$ at $1 \mathrm{kHz}$ ) with a NanoZ-device (Multichannelsystems). To connect to the Intan RHD2164 head stage during recordings, a custom-built adaptor from the Molex SlimStack connector to two 36 Omnetics Nano Strip connectors was used to connect to an Intan RHD2164 head stage amplifier. For the implantation of the recording array, mice were anesthetized with isoflurane, and pre- and post-surgery analgesia was administered. A circular skin patch above the skull was removed. Local anesthesia was applied to the skull. The lateral and nuchal muscle insertions were left intact. The operative field was then prepared by attaching the margins of the remaining skin to the circumference of the top of the skull with VetBond ( $3 \mathrm{M})$, thus protecting soft tissue from damage, contamination, or necrosis and leaving only the surface of the skull exposed. Holes were drilled in the skull above the regions where tetrodes were inserted and for grounding above the cerebellum. The skull was then coated with Super-Bond C\&B (Sun Medical), following the insertion of a small Neuralynx gold pin as ground connected with the recording array through an insulated copper wire. The tetrode array was slowly lowered into the brain with a motorized micromanipulator. The center of the tetrode bundle was targeted from Bregma to anterior $3.0 \mathrm{~mm}$ and lateral $0.8 \mathrm{~mm}$, reaching ventral $3.3 \mathrm{~mm}$ from the dorsal brain surface. After reaching the target depth, dental cement (Kulzer Palladur) was applied at the margins of the recording array so that gravity and capillary force ensured complete filling of the narrow gap between the bottom of the array and the adhesive-coated skull. Animals recovered in their home-cage. The entire surgical procedure took approximately $1 \mathrm{~h}$. Animals were normally fit and eating after less than 30 min. 3-6 weeks after recovery, the mice were placed in the head-fixation setup. The first three sessions were brief $(5-20 \mathrm{~min})$ and served to habituate the animals to head fixation. For odorant delivery, a custom-built air-dilution olfactometer was used [90]. Odorants were kept in the liquid phase (diluted 1:100 in mineral oil) in dark vials and mixed into the nitrogen stream that was further diluted 1:10 into a constant air stream in the olfactometer. The following aldehyde odorants of increasing cchain lengths were used in the experiments: Propanal (CHO3), Butanal (CHO4), n-Pentanal, (CHO5), Hexanal (CHO6), Heptanal (CHO7), Octanal (CHO8), Nonanal (CHO9) (Sigma-Aldrich CAS n. 123-38-6, 123-72-8, 110-623, 66-25-1, 111-71-7, 124-13-0, 124-19-6, respectively). Odorants were each delivered 30 times in a pseudorandomized order with a maximum of 3 consecutive presentations of the same odorant. Odorants were applied for $500 \mathrm{~ms}$ with an inter-trial interval of $10 \mathrm{~s}$. Recordings were performed with an Intan 64 channel RHD 2164 miniature amplifier board connected to a RHD2000 interface board and open-source Intan interface software. Inputs from the olfactometer and sniff sensor were simultaneously recorded with the same interface board. Data were sampled at $30 \mathrm{kHz}$. To monitor the sniff signal, we used a custom-built snout mask that was gently pressed against the snout to generate a cavity in the mask in which pressure fluctuations were continuously measured through an HDI pressure sensor HDIM020GBY8H3 (First Sensor Inc.) connected to the analog input of the RHD2000 interface board (Intan). The mask design is modified based on the original design of Dmitry Rinberg (personal communications). The influx of odorized air into the cavity of the mask was calibrated to the outflow through a continuously measured vacuum. The animals quickly adapted and tolerated the pressure mask. After completion of the experiments, animals were euthanized and perfused with $4 \%$ PFA. Heads were severed with the implants attached and subsequently soaked in 4\% PFA for up to 4 weeks. Due to tissue shrinkage, the exact location of the tetrode tip could not be determined, but revealed preserved electrode tracts in sagittal $150 \mu \mathrm{m}$ sections.

\section{Data processing of in vivo recordings}

For the pre-processing of the recorded data and the spike detection, we subtracted the median voltage trace of all channels from each recorded trace. The resulting signal was 
bandpass filtered between 300 and $5,000 \mathrm{~Hz}$ (4th order Butterworth filter, built-in MATLAB function). A threshold value for spikes was computed as a multiple $(7.5 \times)$ of the median absolute deviation of the filtered signal [91]. Temporally proximal detected peaks over threshold were pruned by height to a minimum distance of $1 \mathrm{~ms}$ to avoid multiple detections of the same multiphasic spike. When an event was detected on multiple channels of a tetrode, the timestamp of the highest detected peak was used. Spike waveforms were extracted around -10 to +21 samples around the peak. Spike sorting was done with a custom-built graphical user interface in MATLAB, originally developed by A. Koulakov (CSHL). Metrics used for clustering included detected peak height or amplitude (and the respective principal components over channels) and the first three principal components of the waveforms for each respective channel when a spike was predominantly recorded on one channel. The quality of single unit clusters was assessed using the mlib toolbox by Maik Stüttgen (Vs. 6, https://de.mathworks. com/matlabcentral/fileexchange/37339-mlib-toolbox-for-ana lyzing-spike-data) with particular attention to peak height distribution (fraction of lost spikes due to detection threshold), contamination (fraction of spikes during the refractory period $<5 \mathrm{~ms}$ ) and waveform variance. The experimenter performing the recordings, spike sorting, and clustering was blinded to the genotypes of the mice.

For further analyzes, units were only included if they complied with a set of criteria: Throughout the analyzed part of the recording session, units were allowed to only have a maximum change in baseline firing rate from beginning to the end of the session of less than $10 \%$ and intermittent maximum fluctuations of $20 \%$. Only units with a baseline firing rate of at least $0.5 \mathrm{~Hz}$ were included for further analysis. Clustering units into putative principal and fast-spiking neurons based on their spike waveform and baseline firing rate do not match the observed features of AON single units (Fig. S11A). Therefore, we examined the whole population of AON neurons together.

Z-scored firing rates were obtained by subtracting the mean baseline firing rate (window of $2 \mathrm{~s}$ before odor onset) from the mean firing rate of each bin and dividing by the baseline standard deviation computed across all trials. For baseline subtracted firing rates, the mean firing rate in a window of $1 \mathrm{~s}$ before odor onset was calculated for each cellodor pair and subtracted from the whole PSTH. For group statistics, Welch's ANOVA test and Dunnett's multiple comparison post-tests were indicated (GraphPad Prism8). The post-test was computed in relation to control mice.

\section{Analysis}

For nCounter- and protein quantification (Fig. 2A, B), the unpaired two-tailed student's t-test was used, and the
$\mathrm{P}$ values were corrected for multiple tests using the Benjamini-Hochberg test. For the cellular physiology (Fig. 2C-F), the paired two-tailed student's $t$ test was used to compare the responses from the paired vs. unpaired input. Data between genotypes were compared by the unpaired two-tailed student's $t$ test and given as means \pm SD. For the Sholl analysis (Fig. 2G, H), One-way ANOVA followed by the turkey multiple comparison test was used. Data were analyzed using Prism6 software (GraphPad, https://www.graphpad.com). All data are shown as mean \pm SEM. For the proteomic analysis, empirical Bayes moderated t-statistics with multiple testing correction by false discovery rate was used ("eBayes" and "topTable" functions from Limma R package). For the behavioral analysis (Fig. 4), the twoway ANOVA test was used to compare the transgenic and control mice using sex and genotype as interacting factors. For the in vivo physiology (Fig. 5), firing ratedata of responses were normalized by either subtracting the baseline from the response or by $z$-scoring the PSTH. The data are shown as mean \pm SEM. The sample sizes of each statistical analysis were: Fig. 5B: 31 sessions in 6 Ctrl. mice, 11 sessions in 4 SH-WT, and 24 sessions in 6 SH-RX. Fig. 5E: all units: Ctrl.: 222, SH-WT: 74, SH-RX: 97; and all excited units: Ctrl.: 58, SH-WT: 21, SH-RX: 18. Fig. 5F: Ctrl.: 123, SH-WT: 22, SH-RX: 55 cell-odor pairs. Fig. 5G: Ctrl.: 253, SHWT: 106, SH-RX: 75 cell-odor pairs. Fig. 5H: Ctrl.: 123, SH-WT: 22, SH-RX: 55 cell-odor pairs. Fig. 5I: Ctrl.: 253, SH-WT: 106, SH-RX: 75 cell-odor pairs. The following statistical tests were used for each analysis for the in vivo physiology: Fig. 5B: ANOVA, Dunnett's post-test, $p=0.45$, Fig. 5E: left: ANOVA, Dunnett's post-test, $p<0.05$, right: ANOVA, Dunnett's post-test, $p=0.0002$, Fig. 5F: ANOVA, Dunnett's post-test, $p<0.0001$, Fig. 5G: ANOVA, Dunnett's posttest, $p<0.0001$, Fig. 5H: ANOVA, Dunnett's post-test, $p=0.0007$, Fig. 5I: ANOVA, Dunnett's post-test, $p<0.0001$.

\section{Data availability}

Proteomics data are available in the Supplementary Data 1 (Dataset 1) https://edmond.mpdl.mpg.de.

Acknowledgments We thank Annette Herold for expert technical assistance and genotyping of mice, Beate Niesler for the support by the nCounter Core Facility, Iryna Paluikhovich for performing mass spectrometric analysis, and Flavia-Bianca Cristian, Beatrix Startt and Claire Bacon for proofreading. Part of this work was published in the $\mathrm{PhD}$ thesis of AE (2019), the Bachelor thesis of AH (2018), and the Master thesis of Kaono Kikui (2018); all at Heidelberg University. The cloning of the tTA responsive SHANK2 expression vectors is described in the Bachelor thesis of MH (2015) at the Mannheim University for Applied Science. 
Author contributions $\mathrm{MH}$ and RS generated and molecularly analyzed the mouse lines. AE designed and performed the behavioral experiments, the protein, and Sholl analysis. CP supervised behavioral studies. AR performed the electrophysiological analysis in the hippocampus. AH participated in the protein analysis. RR carried out the nCounter experiments. SB commented on data interpretation. LO and WK performed and analyzed the in vivo recordings. MG and AS generated the synapse fractions and analyzed their protein composition. $\mathrm{AE}, \mathrm{RS}$, and GR designed the experiments and wrote the manuscript. All authors commented on the manuscript.

Funding Open Access funding enabled and organized by Projekt DEAL. AE was supported by the Heidelberg Biosciences International Graduate School (HBIGS). RS received support from the Ingeborg Ständer Foundation and AR from the RSBF (17-04-01528 A). RR, CP, SB, and GR are supported by the Medical Faculty of the Heidelberg University. WK was supported by a BMBF grant (n. 01GQ1708).

\section{Compliance with ethical standards}

Conflict of interest The authors declare no competing interests.

Publisher's note Springer Nature remains neutral with regard to jurisdictional claims in published maps and institutional affiliations.

Open Access This article is licensed under a Creative Commons Attribution 4.0 International License, which permits use, sharing, adaptation, distribution and reproduction in any medium or format, as long as you give appropriate credit to the original author(s) and the source, provide a link to the Creative Commons license, and indicate if changes were made. The images or other third party material in this article are included in the article's Creative Commons license, unless indicated otherwise in a credit line to the material. If material is not included in the article's Creative Commons license and your intended use is not permitted by statutory regulation or exceeds the permitted use, you will need to obtain permission directly from the copyright holder. To view a copy of this license, visit http://creativecommons. org/licenses/by/4.0/.

\section{References}

1. Peykov S, Berkel S, Schoen M, Weiss K, Degenhardt F, Strohmaier $\mathrm{J}$, et al. Identification and functional characterization of rare SHANK2 variants in schizophrenia. Mol Psychiatry. 2015;20:1489-98.

2. Leblond CS, Nava C, Polge A, Gauthier J, Huguet G, Lumbroso $\mathrm{S}$, et al. Meta-analysis of SHANK Mutations in Autism Spectrum Disorders: a gradient of severity in cognitive impairments. PLoS Genet. 2014;10:e1004580.

3. Ha HTT, Leal-Ortiz S, Lalwani K, Kiyonaka S, Hamachi I, Mysore SP, et al. Shank and zinc mediate an AMPA receptor subunit switch in developing neurons. Front Mol Neurosci. 2018;11:405

4. Jiang YH, Ehlers MD. Modeling autism by SHANK gene mutations in mice. Neuron. 2013;78:8-27.

5. Eltokhi A, Rappold G, Sprengel R. Distinct phenotypes of Shank2 mouse models reflect neuropsychiatric spectrum disorders of human patients with SHANK2 variants. Front Mol Neurosci. 2018; 11:240.

6. Monteiro P, Feng G. SHANK proteins: roles at the synapse and in autism spectrum disorder. Nat Rev Neurosci. 2017;18:147-57.
7. Lee Y-S, Yu N-K, Chun J, Yang J-e, Lim C-S, Kim H, et al. Identification of a novel Shank2 transcriptional variant in Shank2 knockout mouse model of autism spectrum disorder. Mol Brain. 2020;13:54.

8. Halbedl S, Schoen M, Feiler MS, Boeckers TM, Schmeisser MJ. Shank3 is localized in axons and presynaptic specializations of developing hippocampal neurons and involved in the modulation of NMDA receptor levels at axon terminals. J Neurochem. 2016;137:26-32.

9. Wu S, Gan G, Zhang Z, Sun J, Wang Q, Gao Z, et al. A presynaptic function of shank protein in drosophila. J Neurosci. 2017;37:11592-604.

10. Reim D, Distler U, Halbedl S, Verpelli C, Sala C, Bockmann J, et al. Proteomic analysis of post-synaptic density fractions from shank3 mutant mice reveals brain region specific changes relevant to autism spectrum disorder. Front Mol Neurosci. 2017;10:26

11. Shepherd GM. Corticostriatal connectivity and its role in disease. Nat Rev Neurosci. 2013;14:278-91.

12. Berkel S, Marshall CR, Weiss B, Howe J, Roeth R, Moog U, et al. Mutations in the SHANK2 synaptic scaffolding gene in autism spectrum disorder and mental retardation. Nat Genet. 2010;42:489-91.

13. Berkel S, Tang W, Trevino M, Vogt M, Obenhaus HA, Gass P, et al. Inherited and de novo SHANK2 variants associated with autism spectrum disorder impair neuronal morphogenesis and physiology. Hum Mol Genet. 2012;21:344-57.

14. Sheng M, Kim E. The Shank family of scaffold proteins. J Cell Sci. 2000;113:1851-6. Pt 11

15. Du Y, Weed SA, Xiong WC, Marshall TD, Parsons JT. Identification of a novel cortactin SH3 domain-binding protein and its localization to growth cones of cultured neurons. Mol Cell Biol. 1998;18:5838-51.

16. Wang X, Bey AL, Chung L, Krystal AD, Jiang Y-H. Therapeutic approaches for shankopathies. Dev Neurobiol. 2014;74:123-35.

17. Park P, Kang H, Sanderson TM, Bortolotto ZA, Georgiou J, Zhuo $\mathrm{M}$, et al. The role of calcium-permeable AMPARs in long-term potentiation at principal neurons in the rodent hippocampus. Front Synaptic Neurosci. 2018;10:42

18. Okada T, Yamada N, Kakegawa W, Tsuzuki K, Kawamura M, Nawa $\mathrm{H}$, et al. Sindbis viral-mediated expression of $\mathrm{Ca}^{2+}$. permeable AMPA receptors at hippocampal CA1 synapses and induction of NMDA receptor-independent long-term potentiation. Eur J Neurosci. 2001;13:1635-43.

19. Herwig R, Hardt C, Lienhard M, Kamburov A. Analyzing and interpreting genome data at the network level with ConsensusPathDB. Nat Protoc. 2016;11:1889-907.

20. Koopmans F, van Nierop P, Andres-Alonso M, Byrnes A, Cijsouw T, Coba MP, et al. SynGO: an evidence-based, expertcurated knowledge base for the synapse. Neuron. 2019;103:217-34 e214.

21. Gillet LC, Navarro P, Tate S, Röst H, Selevsek N, Reiter L, et al. Targeted data extraction of the MS/MS spectra generated by dataindependent acquisition: a new concept for consistent and accurate proteome analysis*. Mol Cell Proteom. 2012; 11: O111.016717.

22. Ludwig C, Gillet L, Rosenberger G, Amon S, Collins BC, Aebersold R. Data-independent acquisition-based SWATH-MS for quantitative proteomics: a tutorial. Mol Syst Biol. 2018;14:e8126.

23. Goodwin LO, Splinter E, Davis TL, Urban R, He H, Braun RE, et al. Large-scale discovery of mouse transgenic integration sites reveals frequent structural variation and insertional mutagenesis. Genome Res. 2019;29:494-505.

24. Vazquez-Sanchez S, Gonzalez-Lozano MA, Walfenzao A, Li $\mathrm{KW}$, van Weering JRT. The endosomal protein sorting nexin 4 is a synaptic protein. Sci Rep. 2020;10:18239. 
25. Guedes-Dias P, Nirschl JJ, Abreu N, Tokito MK, Janke C, Magiera MM, et al. Kinesin-3 responds to local microtubule dynamics to target synaptic cargo delivery to the presynapse. Curr Biol. 2019;29:268-82.e268.

26. Hamdan FF, Gauthier J, Araki Y, Lin DT, Yoshizawa Y, Higashi $\mathrm{K}$, et al. Excess of de novo deleterious mutations in genes associated with glutamatergic systems in nonsyndromic intellectual disability. Am J Hum Genet. 2011;88:306-16.

27. Yoshikawa K, Kuwahara M, Saigoh K, Ishiura H, Yamagishi Y, Hamano Y, et al. The novel de novo mutation of KIF1A gene as the cause for Spastic paraplegia 30 in a Japanese case. eNeurologicalSci. 2019;14:34-37.

28. Kurihara M, Ishiura H, Bannai T, Mitsui J, Yoshimura J, Morishita $\mathrm{S}$, et al. A novel de novo KIF1A mutation in a patient with autism, hyperactivity, epilepsy, sensory disturbance, and spastic paraplegia. Intern Med. 2020;59:839-42.

29. Grill B, Murphey RK, Borgen MA. The PHR proteins: intracellular signaling hubs in neuronal development and axon degeneration. Neural Dev. 2016;11:8.

30. Bahl S, Chiang C, Beauchamp RL, Neale BM, Daly MJ, Gusella $\mathrm{JF}$, et al. Lack of association of rare functional variants in TSC1/ TSC2 genes with autism spectrum disorder. Mol Autism. 2013;4:5.

31. Grill B, Chen L, Tulgren ED, Baker ST, Bienvenut W, Anderson $\mathrm{M}$, et al. RAE-1, a novel PHR binding protein, is required for axon termination and synapse formation in Caenorhabditis elegans. J Neurosci. 2012;32:2628-36.

32. Pan X, Cao Y, Stucchi R, Hooikaas PJ, Portegies S, Will L, et al. MAP7D2 localizes to the proximal axon and locally promotes kinesin-1-mediated cargo transport into the axon. Cell Rep. 2019;26:1988-99.e1986.

33. Lin AY, Henry S, Reissner C, Neupert C, Kenny C, Missler M, et al. A rare autism-associated MINT2/APBA2 mutation disrupts neurexin trafficking and synaptic function. Sci Rep. 2019;9:6024.

34. Schonkeren SL, Massen M, van der Horst R, Koch A, Vaes N, Melotte V. Nervous NDRGs: the N-myc downstream-regulated gene family in the central and peripheral nervous system. Neurogenetics. 2019;20:173-86.

35. Won H, Lee HR, Gee HY, Mah W, Kim JI, Lee J, et al. Autisticlike social behaviour in Shank2-mutant mice improved by restoring NMDA receptor function. Nature. 2012;486:261-5.

36. Mei Y, Monteiro P, Zhou Y, Kim JA, Gao X, Fu Z, et al. Adult restoration of Shank3 expression rescues selective autistic-like phenotypes. Nature. 2016;530:481-4.

37. Ben Abdallah NM, Fuss J, Trusel M, Galsworthy MJ, Bobsin K, Colacicco G, et al. The puzzle box as a simple and efficient behavioral test for exploring impairments of general cognition and executive functions in mouse models of schizophrenia. Exp Neurol. 2011;227:42-52.

38. Minassian A, Young JW, Cope ZA, Henry BL, Geyer MA, Perry W. Amphetamine increases activity but not exploration in humans and mice. Psychopharmacology. 2016;233:225-33.

39. Lienart F, Morissens M, Jacobs P, Ducobu J. Doxycycline and hepatotoxicity. Acta Clin Belg. 1992;47:205-8.

40. Bannerman DM, Bus T, Taylor A, Sanderson DJ, Schwarz I, Jensen V, et al. Dissecting spatial knowledge from spatial choice by hippocampal NMDA receptor deletion. Nat Neurosci. 2012;15:1153-9.

41. Oettl LL, Kelsch W. Oxytocin and olfaction. Curr Top Behav Neurosci. 2018;35:55-75.

42. Oettl LL, Ravi N, Schneider M, Scheller MF, Schneider P, Mitre $\mathrm{M}$, et al. Oxytocin enhances social recognition by modulating cortical control of early olfactory processing. Neuron. 2016;90:609-21.

43. Walum H, Young LJ. The neural mechanisms and circuitry of the pair bond. Nat Rev Neurosci. 2018;19:643-54.
44. Levy DR, Tamir T, Kaufman M, Parabucki A, Weissbrod A, Schneidman E, et al. Dynamics of social representation in the mouse prefrontal cortex. Nat Neurosci. 2019;22:2013-22.

45. Han K, Holder JL Jr., Schaaf CP, Lu H, Chen H, Kang H, et al. SHANK3 overexpression causes manic-like behaviour with unique pharmacogenetic properties. Nature. 2013;503:72-77.

46. Barkus C, Feyder M, Graybeal C, Wright T, Wiedholz L, Izquierdo A, et al. Do GluA1 knockout mice exhibit behavioral abnormalities relevant to the negative or cognitive symptoms of schizophrenia and schizoaffective disorder? Neuropharmacology. 2012;62:1263-72.

47. Ang G, McKillop LE, Purple R, Blanco-Duque C, Peirson SN, Foster RG, et al. Absent sleep EEG spindle activity in GluA1 (Gria1) knockout mice: relevance to neuropsychiatric disorders. Transl Psychiatry. 2018;8:154.

48. Jensen V, Kaiser KM, Borchardt T, Adelmann G, Rozov A, Burnashev N, et al. A juvenile form of postsynaptic hippocampal long-term potentiation in mice deficient for the AMPA receptor subunit GluR-A. J Physiol. 2003;553:843-56. Pt 3

49. Sarowar T, Grabrucker AM. Actin-dependent alterations of dendritic spine morphology in shankopathies. Neural Plast. 2016;2016:8051861.

50. Yamashita N, Yamane M, Suto F, Goshima Y. TrkA mediates retrograde semaphorin $3 \mathrm{~A}$ signaling through plexin $\mathrm{A} 4$ to regulate dendritic branching. J Cell Sci. 2016;129:1802.

51. Goshima Y, Yamashita N, Nakamura F, Sasaki Y. Regulation of dendritic development by semaphorin 3A through novel intracellular remote signaling. Cell Adh Migr. 2016;10:627-40.

52. Cheadle L, Biederer T. Activity-dependent regulation of dendritic complexity by semaphorin 3A through Farp1. J Neurosci. 2014;34:7999-8009.

53. Zaslavsky K, Zhang W-B, McCready FP, Rodrigues DC, Deneault E, Loo C, et al. SHANK2 mutations associated with autism spectrum disorder cause hyperconnectivity of human neurons. Nat Neurosci. 2019;22:556-64.

54. Durand CM, Perroy J, Loll F, Perrais D, Fagni L, Bourgeron T, et al. SHANK3 mutations identified in autism lead to modification of dendritic spine morphology via an actin-dependent mechanism. Mol Psychiatry. 2012;17:71-84.

55. Baron MK, Boeckers TM, Vaida B, Faham S, Gingery M, Sawaya MR, et al. An architectural framework that may lie at the core of the postsynaptic density. Science. 2006;311:531.

56. Gundelfinger ED, Boeckers TM, Baron MK, Bowie JU. A role for zinc in postsynaptic density asSAMbly and plasticity? Trends Biochem Sci. 2006;31:366-73.

57. Boeckers TM, Liedtke T, Spilker C, Dresbach T, Bockmann J, Kreutz MR, et al. C-terminal synaptic targeting elements for postsynaptic density proteins ProSAP1/Shank2 and ProSAP2/ Shank3. J Neurochem. 2005;92:519-24.

58. Kaeser PS, Deng L, Wang Y, Dulubova I, Liu X, Rizo J, et al. RIM proteins tether $\mathrm{Ca}^{2+}$ channels to presynaptic active zones via a direct PDZ-domain interaction. Cell. 2011;144:282-95.

59. Brockmann MM, Maglione M, Willmes CG, Stumpf A, Bouazza BA, Velasquez LM, et al. RIM-BP2 primes synaptic vesicles via recruitment of Munc13-1 at hippocampal mossy fiber synapses. Elife. 2019;8:e43243.

60. Raynaud F, Janossy A, Dahl J, Bertaso F, Perroy J, Varrault A, et al. Shank3-Rich2 interaction regulates AMPA receptor recycling and synaptic long-term potentiation. $\mathrm{J}$ Neurosci. 2013;33:9699-715.

61. Bissen D, Foss F, Acker-Palmer A. AMPA receptors and their minions: auxiliary proteins in AMPA receptor trafficking. Cell Mol Life Sci. 2019;76:2133-69.

62. Henley JM, Wilkinson KA. AMPA receptor trafficking and the mechanisms underlying synaptic plasticity and cognitive aging. Dialogues Clin Neurosci. 2013;15:11-27. 
63. Fuccillo MV. Striatal circuits as a common node for autism pathophysiology. Front Neurosci. 2016;10:27

64. Bey AL, Wang X, Yan H, Kim N, Passman RL, Yang Y, et al. Brain region-specific disruption of Shank3 in mice reveals a dissociation for cortical and striatal circuits in autism-related behaviors. Transl Psychiatry. 2018;8:94.

65. Mossa A, Pagano J, Ponzoni L, Tozzi A, Vezzoli E, Sciaccaluga M, et al. Developmental impaired Akt signaling in the Shank1 and Shank3 double knock-out mice. Mol Psychiatry. 2021. [Epub ahead of print].

66. Han KA, Yoon TH, Shin J, Um JW, Ko J. Differentially altered social dominance- and cooperative-like behaviors in Shank2- and Shank3-mutant mice. Mol Autism. 2020;11:87.

67. Boeckers TM, Segger-Junius M, Iglauer P, Bockmann J, Gundelfinger ED, Kreutz MR, et al. Differential expression and dendritic transcript localization of Shank family members: identification of a dendritic targeting element in the 3' untranslated region of Shank1 mRNA. Mol Cell Neurosci. 2004;26:182-90.

68. Jerecic J, Schulze CH, Jonas P, Sprengel R, Seeburg PH, Bischofberger J. Impaired NMDA receptor function in mouse olfactory bulb neurons by tetracycline-sensitive NR1 (N598R) expression. Brain Res Mol Brain Res. 2001;94:96-104.

69. Krestel HE, Shimshek DR, Jensen V, Nevian T, Kim J, Geng Y, et al. A genetic switch for epilepsy in adult mice. J Neurosci. 2004;24:10568-78.

70. Mack V, Burnashev N, Kaiser KM, Rozov A, Jensen V, Hvalby $\mathrm{O}$, et al. Conditional restoration of hippocampal synaptic potentiation in Glur-A-deficient mice. Science. 2001;292:2501-4.

71. Sprengel R, Hasan MT. Tetracycline-controlled genetic switches. Handb Exp Pharmacol. 2007; 49-72.

72. Mayford M, Bach ME, Huang YY, Wang L, Hawkins RD, Kandel ER. Control of memory formation through regulated expression of a CaMKII transgene. Science. 1996;274:1678-83.

73. Krestel HE, Mayford M, Seeburg PH, Sprengel R. A GFPequipped bidirectional expression module well suited for monitoring tetracycline-regulated gene expression in mouse. Nucleic Acids Res. 2001;29:E39.

74. Chuhma N, Tanaka KF, Hen R, Rayport S. Functional connectome of the striatal medium spiny neuron. J Neurosci. 2011;31:1183-92.

75. Cross R, Ling C, Day NP, McGready R, Paris DH. Revisiting doxycycline in pregnancy and early childhood-time to rebuild its reputation? Expert Opin Drug Saf. 2016;15:367-82.

76. Wang N, Tian X, Chen Y, Tan H-q, Xie P-j, Chen S-j, et al. Low dose doxycycline decreases systemic inflammation and improves glycemic control, lipid profiles, and islet morphology and function in db/db mice. Sci Rep. 2017;7:14707.

77. Frankwich K, Tibble C, Torres-Gonzalez M, Bonner M, Lefkowitz R, Tyndall $M$, et al. Proof of Concept: Matrix metalloproteinase inhibitor decreases inflammation and improves muscle insulin sensitivity in people with type 2 diabetes. J Inflamm. 2012;9:35

78. Vandesompele J, De Preter K, Pattyn F, Poppe B, Van Roy N, De, et al. Accurate normalization of real-time quantitative RT-PCR data by geometric averaging of multiple internal control genes. Genome Biol. 2002;3:RESEARCH0034.

79. Rozov A, Sprengel R, Seeburg PH. GluA2-lacking AMPA receptors in hippocampal CA1 cell synapses: evidence from genetargeted mice. Front Mol Neurosci. 2012;5:22.

80. Chen HX, Otmakhov N, Lisman J. Requirements for LTP induction by pairing in hippocampal CA1 pyramidal cells. J Neurophysiol. 1999;82:526-32.

81. Pandya NJ, Koopmans F, Slotman JA, Paliukhovich I, Houtsmuller $\mathrm{AB}$, Smit $\mathrm{AB}$, et al. Correlation profiling of brain subcellular proteomes reveals co-assembly of synaptic proteins and subcellular distribution. Sci Rep. 2017;7:12107.

82. Koopmans F, Pandya NJ, Franke SK, Phillippens I, Paliukhovich I, Li KW, et al. Comparative hippocampal synaptic proteomes of rodents and primates: differences in neuroplasticity-related proteins. Front Mol Neurosci. 2018;11:364.

83. He E, Lozano MAG, Stringer S, Watanabe K, Sakamoto K, den Oudsten F, et al. MIR137 schizophrenia-associated locus controls synaptic function by regulating synaptogenesis, synapse maturation and synaptic transmission. Hum Mol Genet. 2018;27:1879-91.

84. Koopmans F, Ho JTC, Smit AB, Li KW. Comparative analyses of data independent acquisition mass spectrometric approaches: DIA, WiSIM-DIA, and untargeted DIA. Proteomics. 2018;18:1700304.

85. Kammers K, Cole RN, Tiengwe C, Ruczinski I. Detecting significant changes in protein abundance. EuPA Open Proteomics. 2015;7:11-19.

86. Ritchie ME, Phipson B, Wu D, Hu Y, Law CW, Shi W, et al. limma powers differential expression analyses for RNAsequencing and microarray studies. Nucleic Acids Res. 2015; 43:e47.

87. Deacon RM. Assessing nest building in mice. Nat Protoc. 2006;1:1117-9.

88. Crawley JN. Mouse behavioral assays relevant to the symptoms of autism. Brain Pathol. 2007;17:448-59.

89. Peleh T, Eltokhi A, Pitzer C. Longitudinal analysis of ultrasonic vocalizations in mice from infancy to adolescence: Insights into the vocal repertoire of three wild-type strains in two different social contexts. PloS One. 2019; 14:e220238.

90. Shusterman R, Smear MC, Koulakov AA, Rinberg D. Precise olfactory responses tile the sniff cycle. Nat Neurosci. 2011;14:1039-44.

91. Quiroga RQ, Nadasdy Z, Ben-Shaul Y. Unsupervised spike detection and sorting with wavelets and superparamagnetic clustering. Neural Comput. 2004;16:1661-87.

\section{Affiliations}

\section{Ahmed Eltokhi $\mathbb{D}^{1,2} \cdot$ Miguel A. Gonzalez-Lozano $\mathbb{C}^{3} \cdot$ Lars-Lennart Oettl $\mathbb{C}^{4} \cdot$ Andrey Rozov $\mathbb{D}^{5,6,7} \cdot$ Claudia Pitzer $^{8}$. Ralph Röth ${ }^{2}$. Simone Berkel $\mathbb{B}^{2} \cdot$ Markus Hüser ${ }^{1} \cdot$ Aliona Harten ${ }^{1}$ - Wolfgang Kelsch $\mathbb{D}^{4,9} \cdot$ August B. Smit $\mathbb{D}^{3}$. Gudrun A. Rappold $\mathbb{D}^{2,10} \cdot$ Rolf Sprengel $\mathbb{I D}^{1,10}$}

1 Research Group of the Max Planck Institute for Medical Research at the Institute for Anatomy and Cell Biology, Heidelberg University, Heidelberg, Germany

2 Department of Human Molecular Genetics, Heidelberg University, Heidelberg, Germany
3 Department of Molecular and Cellular Neurobiology, Center for Neurogenomics and Cognitive Research, Amsterdam Neuroscience, Vrije University Amsterdam, Amsterdam, the Netherlands

4 Central Institute of Mental Health, Medical Faculty Mannheim, Heidelberg University, Mannheim, Germany 
5 Department of Physiology and Pathophysiology, Heidelberg University, Heidelberg, Germany

6 OpenLab of Neurobiology, Kazan Federal University, Kazan, Russia

7 Federal Center of Brain Research and Neurotechnologies, Moscow, Russia
Interdisciplinary Neurobiological Core (INBC), Heidelberg University, Heidelberg, Germany

9 Department of Psychiatry and Psychotherapy, University Medical Center Mainz, Mainz University, Mainz, Germany

10 Interdisciplinary Center for Neurosciences (IZN), Heidelberg University, Heidelberg, Germany 